\title{
CRÓNICA CONSTITUCIONAL DEL AÑO 2005 (I)
}

\author{
POR \\ MIGUEL ÁNGEL PRESNO LINERA \\ Profesor Titular de Derecho Constitucional \\ Universidad de Oviedo \\ presno@uniovi.es \\ http://www.uniovi.es/constitucional/miemb/presno.htm
}

En esta Crónica se realiza una presentación de carácter temático y no exclusivamente cronológica, con el propósito de presentar una panóramica más completa de los sucesos relatados, muchos de los cuales no se han concretado en un momento temporal, sino que han tenido un desarrollo progresivo a lo largo de los doce meses examinados o, incluso, se extienden a años sucesivos. Los grandes bloques temáticos se refieren a la Unión Europea y las relaciones internacionales, los partidos políticos y los procesos electorales, los órganos constitucionales y autonómicos, la organización territorial del Estado, y los derechos, deberes y libertades de los ciudadanos.

\section{UNIÓN EUROPEA Y RELACIONES INTERNACIONALES}

En el ámbito de la Unión Europea deben recordarse los siguientes eventos: el 29 de octubre de 2004, los Jefes de Estado y de Gobierno y los Ministros de Asuntos Exteriores de la Unión Europea firmaron en Roma el Tratado por el que se establece una Constitución para Europa. Los países de la Unión disponen de un plazo de dos años para ratificar el Tratado.

Por lo que se refiere al proceso de ratificación del Tratado en España, deben señalarse los siguientes hitos: el 5 de noviembre, el Consejo 
de Ministros acordó hacer uso del artículo 95.2 de la Constitución para requerir al Tribunal Constitucional que se pronunciase sobre si esa ratificación exigía una previa revisión de la Constitución de 1978. El Tribunal Constitucional, en su Declaración 1/2004, de 13 de diciembre, respondió «que no existe contradicción entre la Constitución española y el artículo l-6 del Tratado por el que se establece una Constitución para Europa, firmado en Roma el 29 de octubre de 2004»; "que no existe contradicción entre la Constitución española y los arts. II-111 y II112 de dicho Tratado" y "que el artículo 93 de la Constitución española es suficiente para la prestación del consentimiento del Estado al Tratado referido"; se formularon tres Votos particulares discrepantes.

Tras la Declaración del Tribunal Constitucional, el Gobierno, una vez obtenida la autorización del Congreso de los Diputados, aprobó el Real Decreto 5/2005, de 14 de enero (BOE n. ${ }^{\circ}$ 13, de 15 de enero), "por el que se somete a referéndum consultivo de la Nación la decisión política de ratificar el Tratado por el que se establece una Constitución para Europa». La fecha de la consulta fue el 20 de febrero y se produjeron los siguientes resultados: 10.804 .464 votos favorables a la ratificación (76,73\%); 2.428 .409 contrarios (17,24\%); 849.03 en blanco $(6,03 \%)$ y 122.697 nulos $(0,86 \%)$; la participación fue del $42,32 \%$.

En el ámbito legislativo interno, deben citarse la Ley Orgánica $1 / 2005$, de 20 de mayo, por la que se autoriza la ratificación por España del Tratado por el que se establece una Constitución para Europa, firmado en Roma el 29 de octubre de 2004 (BOE n. 121 , de 21 de mayo) y la Ley Orgánica 6/2005, de 22 de diciembre, por la que se autoriza la ratificación por España del Tratado de Adhesión a la Unión Europea de la República de Bulgaria y de la República de Rumanía (BOE n. ${ }^{\circ}$ 306, de 23 de diciembre).

Por lo que respecta a la trasposición de Directivas comunitarias al ordenamiento jurídico español hay que señalar que, en el momento de concluir estas líneas ( 1 de marzo de 2006), están pendientes un total de 121 (41 con plazo vencido y 80 con plazo no vencido).

Debe destacarse también la decisión del Consejo de Ministros de Asuntos Generales y Relaciones Exteriores, de 13 de junio, admitiendo el empleo de todas las lenguas cooficiales españolas para las comunicaciones con las instituciones comunitarias.

En el ámbito jurisprudencial, y a propósito de los litigios en los que ha sido parte el Estado español, cabe recordar las siguientes sentencias²:

2 Disponibles en http://curia.eu.int/es/content/juris/index rep.htm 
1) la Sentencia del Tribunal de Justicia (Sala Segunda) de 13 de enero de 2005, resolvió:

que el Reino de España ha incumplido las obligaciones que le incumben en virtud de las Directivas 93/36/CEE del Consejo, de 14 de junio de 1993, sobre coordinación de los procedimientos de adjudicación de contratos públicos de suministro y 93/37/CEE del Consejo, de 14 de junio de 1993, sobre coordinación de los procedimientos de adjudicación de los contratos públicos de obras, al no haber adaptado correctamente su ordenamiento jurídico interno a las citadas Directivas y, en particular:

- al excluir del ámbito de aplicación del Texto Refundido de la Ley de Contratos de las Administraciones Públicas, de 16 de junio de 2000, aprobado mediante el Real Decreto Legislativo 2/2000, de 16 de junio, $y$, en concreto, en el artículo 1, apartado 3, de dicho Texto Refundido a las entidades de Derecho privado que reúnan los requisitos recogidos en el artículo 1, letra b), párrafo segundo, guiones primero, segundo y tercero, de cada una de las mencionadas Directivas;

- al excluir de forma absoluta del ámbito de aplicación del Texto Refundido y, en concreto, en el artículo 3, apartado 1, letra c), de éste los convenios de colaboración que celebren las Administraciones Públicas con las demás entidades públicas $y$, por tanto, también los convenios que constituyan contratos públicos a efectos de dichas Directivas, $y$

- al permitir en los artículos 141 , letra a), y 182, letras a) y g), del Texto Refundido que se recurra al procedimiento negociado en dos supuestos que no están contemplados en las citadas Directivas.

2) La sentencia del Tribunal de Justicia (Sala Segunda), de 14 de abril, declaró:

que el Reino de España ha incumplido las obligaciones que le incumben en virtud de las Directivas 68/360/CEE del Consejo, de 15 de octubre de 1968 , sobre supresión de restricciones al desplazamiento y a la estancia de los trabajadores de los Estados miembros y de sus familias dentro de la Comunidad, 73/148/CEE del Consejo, de 21 de mayo de 1973, relativa a la supresión de las restricciones al desplazamiento y a la estancia, dentro de la Comunidad, de los nacionales de los Estados miembros en materia de establecimiento y de prestación de servicios, 90/365/CEE del Consejo, de 28 de junio de 1990, relativa al derecho de residencia de los trabajadores por cuenta ajena o por cuenta propia que hayan dejado de ejercer su actividad profesional y 64/221/CEE del Consejo, de 25 de febrero de 1964, para la coordinación de las medidas especiales para los extranjeros en materia de desplazamiento y de residencia, justificadas por razones de orden público, seguridad y salud pública:

- al no haber adaptado correctamente su ordenamiento jurídico interno a las Directivas 68/360, 73/148 y 90/365 y, en particular, al imponer 
a los nacionales de un país tercero, que sean miembros de la familia de un nacional comunitario que ha ejercido su derecho de libre circulación, la obligación de obtener un visado de residencia para la expedición del permiso de residencia, y

- al no conceder el permiso de residencia en el más breve plazo, y a más tardar, dentro de los seis meses siguientes a la presentación de la solicitud de dicho permiso, en contra de lo dispuesto en la Directiva $64 / 221$.

3) La sentencia del Tribunal de Justicia (Sala Tercera), de 28 de abril, concluyó

que el Reino de España ha incumplido las obligaciones que le incumben en virtud de la Directiva 2001/29/CE del Parlamento Europeo y del Consejo, de 22 de mayo de 2001, relativa a la armonización de determinados aspectos de los derechos de autor y derechos afines a los derechos de autor en la sociedad de la información, al no haber adoptado las disposiciones legales, reglamentarias y administrativas necesarias para dar cumplimiento a lo dispuesto en dicha Directiva.

4) La sentencia del Tribunal de Justicia (Sala Tercera), de 6 de octubre, declaró

que el Reino de España ha incumplido las obligaciones que le incumben en virtud del Derecho comunitario y, en particular, de los artículos 17, apartados 2 y 5 , y 19 de la de la Directiva 77/388/CEE del Consejo, de 17 de mayo de 1977, Sexta Directiva en materia de armonización de las legislaciones de los Estados miembros relativas a los impuestos sobre el volumen de negocios - Sistema común del impuesto sobre el valor añadido: base imponible uniforme, en su versión modificada por la Directiva 95/7/CE del Consejo, de 10 de abril de 1995, al prever una prorrata de deducción del impuesto sobre el valor añadido soportado por los sujetos pasivos que efectúan únicamente operaciones gravadas y al instaurar una norma especial que limita el derecho a la deducción del IVA correspondiente a la compra de bienes o servicios financiados mediante subvenciones.

En lo que tiene que ver con la actividad normativa derivada de las relaciones internacionales de nuestro país, hay que hacer mención a la publicación de los siguientes Convenios:

Instrumento de Ratificación del Protocolo de 2003 relativo al Convenio Internacional sobre la constitución de un Fondo Internacional de Indemnización de daños debidos a contaminación por hidrocarburos, 1992, hecho en Londres el 16 de mayo de 2003 (BOE n. ${ }^{\circ} 28$, de 2 de febrero); 
Instrumento de Ratificación del Protocolo de Kyoto al Convenio Marco de las Naciones Unidas sobre el Cambio Climático, hecho en Kyoto el 11 de diciembre de 1997 (BOE n. ${ }^{\circ}$ 33, de 8 de febrero); Instrumento de Ratificación del Convenio Marco de la OMS para el control del tabaco, hecho en Ginebra el 21 de mayo de 2003 (BOE n. ${ }^{\circ}$ 35, de 10 de febrero de 2005); al Instrumento de Ratificación del Acuerdo entre los Estados parte en el Convenio para el establecimiento de una Agencia Espacial Europea y la Agencia Espacial Europea para la protección y el intercambio de información clasificada, hecho en París el 19 de agosto de 2002 (BOE n. ${ }^{\circ}$ 53, de 3 de marzo de 2005); Instrumento de Ratificación del Convenio Internacional sobre Salvamento Marítimo, 1989, hecho en Londres el 28 de abril de 1989 (BOE n. ${ }^{\circ}$ 57, de 8 de marzo); Protocolo del Convenio relativo a la asistencia judicial en materia penal entre los Estados miembros de la Unión Europea, celebrado por el Consejo de conformidad con el artículo 34 del Tratado de la Unión Europea, hecho en Luxemburgo el 16 de octubre de 2001. Aplicación provisional (BOE n. ${ }^{\circ} 89$, de 14 de abril) y el Tratado sobre el Estatuto de EUROFOR, hecho en Roma el 5 de julio de 2000 (BOE n. ${ }^{\circ}$ 108, de 6 de mayo).

El Estado español, por medio de tres notas verbales de 22 de diciembre, ha denunciado varios Convenios:

el Convenio Internacional para la unificación de ciertas reglas relativas a la limitación de la responsabilidad de los propietarios de buques y Protocolo de firma, hecho en Bruselas el 25 de agosto de 1924; el Convenio Internacional relativo a la limitación de la responsabilidad de los propietarios de buques que navegan por alta mar, hecho en Bruselas el 10 de octubre de 1957, y el Protocolo que modifica el Convenio Internacional de 10 de octubre de 1957, relativo a la limitación de la responsabilidad de propietarios de buques que navegan por el mar, hecho en Bruselas el 21 de diciembre de 1979. Estas Denuncias surtirán efecto para España el 4 de enero de 2006 (BOE n. ${ }^{\circ} 52$, de 2 de marzo de 2005).

Por su parte, en la reunión de Ginebra, del 18 de octubre al 5 de noviembre, el Comité de Derechos Humanos de la ONU aprobó un Dictamen en el que considera vulnerado por España el derecho a la doble instancia penal establecido en el Pacto Internacional de Derechos Civiles y Políticos, por entender que el recurso de casación ante el Tribunal Supremo no cubre esas exigencias al no permitirse la revisión de las pruebas.

Haciéndose eco de reiteradas declaraciones de esta índole, el 26 de diciembre de 2005 el Gobierno remitió a las Cortes Generales el Proyecto de Ley Orgánica por la que se adapta la legislación procesal a la Ley Orgánica 6/1985, de 1 de julio, del Poder Judicial, se reforma el recurso de casación y se generaliza la doble instancia penal, en cuya Ex- 
posición de Motivos se puede leer que el Proyecto se dirige «de un lado, a culminar la generalización de la segunda instancia penal que, iniciada en la Ley Orgánica del Poder Judicial tras la reforma efectuada por la Ley Orgánica 19/2003, de 23 de diciembre, diseña el procedimiento a seguir para satisfacer las exigencias derivadas del artículo 14.5 del Pacto Internacional de Derecho Civiles y Políticos, ante las reiteradas resoluciones del Comité de Derechos Humanos de la ONU que declaran el incumplimiento de España del citado precepto ${ }^{3}$.

\section{PARTIDOS POLÍTICOS Y PROCESOS ELECTORALES}

A propósito de los procesos electorales, y en lo que afecta a las reformas legislativas, han de mencionarse la Ley 4/2005, del Parlamento Vasco, de 18 de febrero, de igualdad de mujeres y hombres (BOPV $n .{ }^{\circ}$ 42 , de 2 de marzo) y la Ley 5/2005, de 8 de abril, por la que se modifica la Ley 1/1986, de 2 de enero, Electoral de Andalucía (BOJA n. ${ }^{\circ}$ 74, de 18 de abril).

La primera, en su Disposición Final Cuarta, incluye la modificación de la Ley 5/1990, de 15 de junio, de Elecciones al Parlamento Vasco, con el siguiente texto:

"Las candidaturas que presenten los partidos políticos, federaciones, coaliciones o agrupaciones de personas electoras estarán integradas por al menos un $50 \%$ de mujeres. Se mantendrá esa proporción en el conjunto de la lista de candidatos y candidatas y en cada tramos de seis nombres. Las Juntas electorales del territorio histórico competente sólo admitirán aquellas candidaturas que cumplan con lo señalado en este artículo tanto para las personas candidatas como para las suplentes".

Con el mismo fin, también se modificó la Ley 1/1987 de 27 de marzo, de Elecciones para las Juntas Generales de los Territorios Histórico de Araba, Bizkaia y Guipúzcoa.

Por su parte, la Ley aprobada por el Parlamento de Andalucía modificó el artículo 23 de la Ley Electoral de Andalucía, dándole la siguiente redacción:

"La presentación de candidaturas, en la que se alternarán hombres y mujeres, habrá de realizarse entre el decimoquinto y el vigésimo días

${ }^{3}$ El Proyecto y su discurrir parlamentario pueden consultarse en http://www.congreso.es/ 
posteriores a la convocatoria, mediante listas que deben incluir tantos candidatos como escaños a elegir por cada circunscripción y además cuatro candidatos suplentes, expresándose el orden de colocación de todos ellos, ocupando los de un sexo los puestos impares y los del otro los pares".

Respecto a las convocatorias electorales a lo largo del año 2005 han de citarse las elecciones al Parlamento Vasco y al Parlamento de Galicia. En las elecciones al Parlamento Vasco se produjeron los siguientes resultados: la coalición, EAJ-PNV/EA obtuvo 468.117 votos y 29 escaños; PSE-EE/PSOE, 274.546 votos y 18 escaños; Partido Popular, 210.614 votos y 15 escaños; Partido Comunista de las Tierras VascasEHAK, 150.644 votos y 9 escaños; Ezker Batua, 65.023 votos y 3 escaños y Aralar, 28.180 votos y 1 escaño 4 .

Antes de la celebración de las elecciones vascas, el Tribunal Constitucional, a través de la STC 68/2005, de 31 de marzo, resolvió el recurso de amparo electoral interpuesto por la candidatura de la agrupación de electores Aukera Guztiak (AG) en los territorios históricos de Álava, Guipúzcoa y Vizcaya, contra la Sentencia de la Sala del artículo 61 de la Ley Orgánica del Poder Judicial, de 26 de marzo de 2005, recaída en los recursos contencioso-electorales núms. 7 y 8-2005, que anuló los Acuerdos de las Juntas Electorales de los territorios históricos de Álava, Guipúzcoa y Vizcaya, de fecha 22 de marzo de 2005, de proclamación de las candidaturas presentadas en dichos territorios históricos por la agrupación de electores demandante de amparo.

El Tribunal Constitucional concluyó que:

"el Tribunal Supremo ha entendido, de manera razonable y fundada, que la genérica condena de la violación de los derechos humanos por parte de la actora no alcanza a operar en este caso como contrapeso suficiente a los fines de desvirtuar tales indicios. En otros términos, la Sentencia recurrida discurre en el marco de la jurisprudencia que acabamos de citar, al constatar la inexistencia de una condena del terrorismo, el cual no es lamentablemente una mera abstracción, sino una realidad concreta, perfectamente definida, ante la que no tiene el mismo valor significativo la condena genérica de la vulneración de los derechos civiles y políticos de cualquiera, que es la única a la que se refiere la recurrente y a la que es atribuible un cierto sentido de abstracción, que la condena concreta del terrorismo, que implica un referente subjetivo mucho más preciso, y que de existir constituiría el contraindicio referido en nuestra

${ }_{4}$ Pueden consultarse en http://parlamento.euskadi.net 
jurisprudencia $\varkappa^{5}$. Por ello, el Tribunal Constitucional decidió desestimar el recurso de amparo promovido por la agrupación de electores Aukera Guztiak.

En las elecciones al Parlamento de Galicia, el Partido Popular obtuvo 756.562 votos y 37 diputados; el PSdeG-PSOE 555.603 votos y 25 Diputados, y el Bloque Nacionalista Galego 311.954 votos y 13 Diputa$\operatorname{dos}^{6}$.

En lo que respecta a la financiación de los partidos políticos, el Tribunal de Cuentas aprobó, en sesión celebrada el 27 de octubre de 2005, el Informe de Fiscalización de la Contabilidad de los Partidos Políticos del ejercicio 2002 y acordó la elevación de dicho Informe a las Cortes Generales ${ }^{7}$.

De los resultados de la fiscalización se deducen las siguientes conclusiones relativas al cumplimiento por parte de los partidos políticos de las normas referidas a las obligaciones contables contenidas en la Ley Orgánica 3/1987, así como al cumplimiento de las prescripciones que sobre los recursos económicos de los partidos políticos se establecen en la citada Ley.

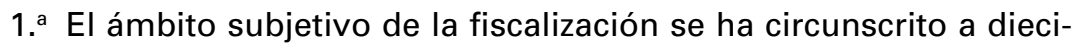
séis partidos políticos que en el año 2002 han percibido, directamente o indirectamente a través de la correspondiente federación en la que estén integrados, subvenciones del Estado para su funcionamiento ordinario, más una coalición electoral que, si bien no percibe directamente subvenciones anuales de funcionamiento ordinario, mantiene la titularidad de los grupos institucionales y responde de las deudas electorales derivadas de la concurrencia a los distintos procesos celebrados. Todas estas formaciones han presentado las cuentas anuales del ejercicio 2002 ante el Tribunal de Cuentas, si bien una de ellas (EA) lo ha hecho fuera del plazo establecido en la Ley Orgánica 3/1987, con una demora de más de un año. Entre los documentos que integran las cuentas anuales, tres formaciones políticas (EA, PCE y UDC) no incluyen la memoria del ejercicio prevista en la actualización de las Directrices Técnicas para la fiscalización de la contabilidad anual, aprobadas por el Pleno del Tribunal de Cuentas y comunicadas a las formaciones políticas. Por otra parte, cuatro formaciones políticas (PA, PCE, PNV y PSC) no disponen de un inventario anual de todos los bienes debidamente actualizado y valorado, previsto

${ }^{5}$ Sentencia disponible en http://www.tribunalconstitucional.es/JC.htm

${ }^{6}$ Información electoral y parlamentaria disponible en la página del Parlamento gallego: http://www.parlamentodegalicia.com.

${ }^{7}$ El Informe puede consultarse en http://www.tcu.es 
en el artículo 9.2.a) de la Ley Orgánica 3/1987 sobre financiación de los partidos políticos.

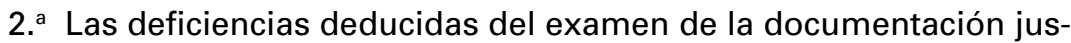
tificativa de las cuentas anuales de la formación política Partido Andalucista, especialmente la relacionada con la deuda bancaria, limitan significativamente la representatividad de las mismas. Por otra parte, para la formación política Izquierda Unida, la falta de fiscalización de los estados financieros de una parte significativa de la organización territorial (sólo ha presentado la contabilidad de dos federaciones territoriales) ha supuesto una importante limitación al alcance de la fiscalización que ha impedido valorar adecuadamente los posibles efectos sobre las cuentas anuales.

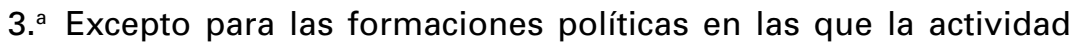
económica de la estructura local está centralizada, las cuentas anuales del resto de las formaciones no presentan en toda su amplitud la actividad económico-financiera de la organización local ni la de los grupos políticos en las Corporaciones Locales, carencia que adquiere una especial relevancia por lo que se refiere a las cuotas de los afiliados recaudadas en dicho ámbito y a la actividad económica desarrollada en los municipios con una importante población. Por otra parte, en la mayoría de las formaciones políticas con representación en el Parlamento Europeo, no figura incluida la contabilidad de la representación parlamentaria correspondiente. Estas omisiones quebrantan la concepción del partido político como una única realidad económico-financiera en la que se ha de integrar toda su organización territorial e institucional, como reiteradamente se ha pronunciado el Tribunal de Cuentas, y ocasionan una limitación al alcance de la fiscalización, como se señala, en su caso, en el apartado del Informe correspondiente a cada formación política. Respecto a dicha limitación, hay que destacar que, pese a su reiteración en sucesivos ejercicios, no se observa una reducción significativa en ámbito de la actividad no incluida en los estados financieros, persistiendo prácticamente la misma situación.

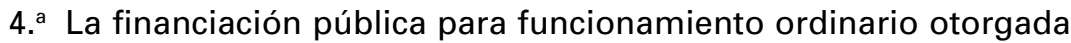
en el ejercicio 2002 a los partidos políticos ha sido de 156,6 millones de euros, según resulta de las comunicaciones remitidas por las Instituciones otorgantes a las que el Tribunal de Cuentas les ha solicitado información. Por otra parte, las subvenciones electorales recibidas en el año 2002, procedentes fundamentalmente de liquidaciones derivadas de elecciones celebradas en ejercicios anteriores, han ascendido a 2,4 millones de euros. De las subvenciones para funcionamiento ordinario recibidas, 38,9 millones de euros corresponden a las subvenciones otorgadas por las Corporaciones Locales a los grupos políticos constituidos en las mismas y 3,6 millones de euros a las concedidas por el Gobierno del País Vasco para el funcionamiento ordinario de los partidos políticos con representación en el Parlamento Vasco, recursos no incluidos entre 
las fuentes de financiación pública enumeradas en el artículo 2 de la Ley Orgánica 3/1987.

Respecto a las subvenciones de las Corporaciones Locales, con independencia de la valoración jurídica ya expresada sobre la regulación de este tipo de financiación, incorporada, tras su modificación, en la Ley Reguladora de las Bases del Régimen Local, en relación con la Ley Orgánica 3/1987, norma reguladora específica de esta materia, en la que dicha financiación no está contemplada, se ha observado que las formaciones políticas, con carácter general, no incluyen en las cuentas anuales presentadas la totalidad de las aportaciones recibidas. En contra de los argumentos expuestos por las formaciones políticas para justificar la no incorporación de estas aportaciones en la contabilidad rendida, es preciso señalar que las operaciones de los grupos de cargos electos forman parte de la actividad del partido, considerado como una unidad económica, sin perjuicio de que lleven su propia contabilidad, que se deberá consolidar con la del resto del partido, y de las obligaciones previstas ante los órganos otorgantes para justificar su aplicación, así como de la conveniencia de que dicha subvención atienda a la finalidad para la que fue creada y sea el resultado de la correcta evaluación de los costes originados por la actividad subvencionable.

Para los partidos con representación en el Parlamento de Cataluña, hay que destacar la concesión de asignaciones extraordinarias concedidas por el mismo en este ejercicio a los grupos parlamentarios con representación en dicha Cámara por un importe total de 4,5 millones de euros. Con independencia de los criterios seguidos en su concesión y de la singularidad de esta operación de financiación del Parlamento de Cataluña mediante transferencia de crédito procedente de Secciones presupuestarias del Gobierno de la Generalidad, dadas las prerrogativas de autonomía reglamentaria, organizativa y presupuestaria que garantizan la independencia de aquél, se ha comprobado que este procedimiento se viene utilizando en sucesivos ejercicios, al tiempo que no se ajusta a lo previsto en el citado artículo 2 de la Ley Orgánica 3/1987, en cuanto a las fuentes de recursos públicos para su actividad ordinaria de los partidos políticos al no haberse dedicado en todos los casos al funcionamiento de los Grupos de dicha Asamblea Legislativa.

5. ${ }^{\text {a }}$ De acuerdo con los registros contables, las aportaciones privadas no finalistas recibidas por las formaciones políticas suman 9,6 millones de euros. Las aportaciones nominativas han respetado con carácter general las previsiones establecidas en la Ley Orgánica 3/1987, excepto en las formaciones políticas Partido Popular y Convergencia Democrática de Catalunya, en las que no consta, como se prevé en el artículo 5.2 de esa misma Ley, el acuerdo adoptado por el órgano social competente para las aportaciones procedentes de personas jurídicas, por un total de $64.442,21$ y 21.000 euros, respectivamente. En cuanto a las aportaciones anónimas, cuyo total asciende a 8,8 millones de euros, dada su natura- 
leza, no se ha podido comprobar el cumplimiento del límite legal establecido para las aportaciones procedentes de una misma persona. Por el contrario, se ha comprobado que la cuantía total recibida por cada uno de los partidos no ha sobrepasado el límite del 5 por 100 de la cantidad asignada en los Presupuestos Generales del Estado para atender la subvención pública prevista en la citada ley Orgánica.

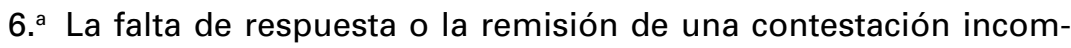
pleta por parte de algunas de las entidades financieras a las que los partidos políticos han solicitado, a instancia del Tribunal de Cuentas, información sobre los saldos mantenidos ha constituido una limitación sobre la verificación de las operaciones bancarias formalizadas por las formaciones políticas, con el alcance que se recoge para cada una de ellas. Analizando esta limitación en su conjunto, y en relación con las operaciones de endeudamiento al ser las más significativas en cuanto a su cuantía, hay que señalar que seis entidades de crédito no han contestado a la solicitud de información sobre siete partidos políticos, cuya deuda contabilizada suma 18,3 millones de euros. Por otra parte, en los escritos de contestación enviados, cinco entidades de crédito no informan sobre determinadas operaciones de endeudamiento que figuran en la contabilidad, afectando a cuatro formaciones por un total de $8,8 \mathrm{mi}$ llones de euros.

7. ${ }^{\text {a }}$ De las comprobaciones sobre las operaciones de endeudamiento con entidades de crédito contabilizadas, se deducen las siguientes deficiencias en su registro contable y control interno: diferencias entre los saldos comunicados por las entidades de crédito y los importes contabilizados, especialmente por los intereses devengados correspondientes a operaciones vencidas; operaciones formalizadas a nombre de miembros del partido cuyos fondos están a disposición del mismo, siendo éste el que atiende a su pago; y existencia de operaciones que no han sido objeto de amortización en los plazos vencidos. De acuerdo con los estados contables presentados, la deuda vencida total asciende, al menos, a 38,1 millones de euros, que se distribuye entre ocho formaciones políticas (CIU, ERC, EA, IU, PA, PSOE, PSC y UDC).

8. ${ }^{\text {a }}$ Se ha cancelado en el ejercicio una operación de crédito, proveniente de 1998, mediante la formalización de una nueva operación suscrita por Unión Democrática de Catalunya y la entidad financiera prestamista. En la cancelación de dicha deuda, se han regularizado parte de los intereses que figuraban contabilizados, por 53.305,42 euros, habiéndose aportado como documentación acreditativa únicamente la nueva póliza formalizada. Hay que destacar que esta operación supone una aportación extraordinaria para el partido no regulada expresamente en la Ley Orgánica 3/1987.

9. ${ }^{\text {a }}$ En este ejercicio se ha continuado con las devoluciones a dos formaciones políticas (PCE y PNV) realizadas por el Estado al amparo de la Ley $43 / 1998$, de 15 de diciembre, de Restitución o Compensación a los 
Partidos Políticos de Bienes y Derechos Incautados en aplicación de la normativa sobre responsabilidades políticas del periodo 1936-1939, por un importe total de 31.672 y 938.630 euros respectivamente.

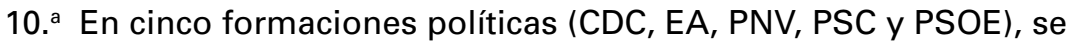
han observado participaciones en el capital de diversas sociedades mercantiles. El objeto social de estas sociedades lo constituye, fundamentalmente, la tenencia y administración de bienes inmobiliarios y actividades promotoras de construcción de sedes y locales para uso del partido. La fiscalización de la inversión financiera mantenida en sociedades mercantiles, cuando la participación es mayoritaria y directa, se ha limitado a comprobar que el valor de la inversión se ajusta a los principios contables con las salvedades y resultados reflejados en los apartados correspondientes a cada una de las formaciones. El Tribunal de Cuentas considera necesario establecer en la normativa aplicable mecanismos de control sobre la incidencia que las relaciones de las formaciones políticas con las sociedades mercantiles pudieran presentar en su financiación y actividad.

11. ${ }^{a}$ En los resultados de los últimos informes, así como en la Moción remitida a las Cortes Generales, se viene poniendo de manifiesto las relaciones que la mayoría de los partidos políticos mantienen con diversas fundaciones, referidas a su constitución, a la concesión de préstamos o subvenciones de funcionamiento, a la adquisición de inmuebles por parte de la fundación y la posterior cesión de uso al partido, y al ingreso en la fundación de las aportaciones realizadas por los cargos públicos. No obstante, como se viene indicando en los distintos informes, se aprecia una insuficiente regulación del marco normativo básico de la actividad de los partidos políticos en relación con las fundaciones vinculadas a los mismos con arreglo a los principios de transparencia y publicidad. En el ejercicio 2002, figuran entregas de fondos a fundaciones por un total de 1,7 millones de euros registradas en la contabilidad de ocho formaciones políticas y una deuda con una fundación en otra formación, con un saldo final de 0,7 millones de euros.

\section{Recomendaciones.}

El Pleno del Tribunal de Cuentas, en su sesión de 30 de octubre de 2001, aprobó la Moción relativa a la modificación de la normativa sobre financiación y fiscalización de los partidos políticos, en la que se sistematizan las deficiencias e irregularidades deducidas de los sucesivos informes aprobados por el Tribunal de Cuentas sobre la fiscalización de las cuentas anuales y de la contabilidad electoral de los partidos políticos, y en la que se exponen las correspondientes recomendaciones encaminadas a la subsanación de las mismas. Dado que las deficiencias e insuficiencias puestas de manifiesto en la Moción siguen vigentes en el ejercicio fiscalizado a que hace referencia este Informe, el Tribunal de Cuentas reitera de nuevo las recomendaciones en ella efectuadas, en la pretensión de que dichas recomendaciones sean consideradas, en su 
caso, en el proceso de reforma de la Ley Orgánica sobre financiación de los partidos políticos cuyo inicio se acordó por unanimidad por el Pleno del Congreso del pasado 27 de septiembre, en consonancia con las sucesivas resoluciones adoptadas por la Comisión Mixta Congreso-Senado para las relaciones con el Tribunal de Cuentas, en las que se ha venido reiterando la asunción de la práctica totalidad de las propuestas recogidas en la Moción mencionada.

\section{III. ÓRGANOS CONSTITUCIONALES Y AUTONÓMICOS}

En lo relativo a las Cortes Generales ha de comenzarse recordando que el Reglamento del Senado resultó modificado para ampliar el uso de las lenguas cooficiales (BOE n. ${ }^{\circ} 159$, de 5 de julio).

Artículo primero. Se suprime el apartado 2 del artículo 56 bis 7.

Artículo segundo. Se añade un artículo 56 bis 9 (nuevo) con la siguiente redacción: "Las intervenciones que se produzcan en las sesiones de la Comisión General de las Comunidades Autónomas podrán realizarse en cualquiera de las lenguas que, con el castellano, tengan el carácter de oficiales en alguna Comunidad Autónoma, de acuerdo con la Constitución y el correspondiente Estatuto de Autonomía. En el Diario de Sesiones se reproducirán íntegramente en la lengua en que se hayan realizado y en castellano.»

Artículo tercero. Se añade un apartado 2 (nuevo) al artículo 191 con la siguiente redacción:

"Si el autor de una moción, interpelación o pregunta la presenta en castellano y además en una lengua que tenga el carácter de oficial en alguna Comunidad Autónoma, de acuerdo con la Constitución y el correspondiente Estatuto de Autonomía, la iniciativa se publicará también en esta lengua."

En lo que se refiere a los Reglamentos de los Parlamentos de las Comunidades Autónomas, han de citarse el nuevo Reglamento el Parlamento de Andalucía, aprobado por el Pleno los días 28 y 29 de septiembre (BOPA n. ${ }^{\circ} 292$, de 4 de octubre, y BOJA n. ${ }^{\circ} 198$, de 10 de octubre $)^{8}$, y el Reglamento del Parlamento de Cataluña, aprobado por el Pleno el día 22 de diciembre de 2005 (DOGC n. ${ }^{\circ}$ 4553, de 18 de enero de 2006) $)^{9}$.

8 Puede leerse en http://www.parlamentodeandalucia.es/

${ }^{9}$ http://www.parlament-cat.net/ 
Por lo que respecta a la actividad legislativa de las Cortes Generales, se aprobaron a lo largo del año 20056 Leyes Orgánicas y 30 Leyes Ordinarias, de cuyo contenido se dará cuenta más adelante.

\section{Las 6 Leyes Orgánicas fueron:}

Ley Orgánica 1/2005, de 20 de mayo, por la que se autoriza la ratificación por España del Tratado por el que se establece una Constitución para Europa, firmado en Roma el 29 de octubre de 2004 (BOE n. ${ }^{\circ} 121$, de 21 de mayo); Ley Orgánica 2/2005, de 22 de junio, de modificación del Código Penal (BOE n. ${ }^{\circ}$ 149, de 23 de junio); Ley Orgánica 3/2005, de 8 de julio, de modificación de la Ley Orgánica 6/1985, de 1 de julio, del Poder Judicial, para perseguir extraterritorialmente la práctica de la mutilación genital femenina (BOE n. ${ }^{\circ} 163$, de 9 de julio); Ley Orgánica 5/2005, de 17 de noviembre, de la Defensa Nacional (BOE n. ${ }^{\circ} 276$, de 18 de noviembre); Ley Orgánica 6/2005, de 22 de diciembre, por la que se autoriza la ratificación por España del Tratado de Adhesión a la Unión Europea de la República de Bulgaria y de la República de Rumanía (BOE n. ${ }^{\circ} 306$, de 23 de diciembre).

\section{Las 30 Leyes Ordinarias:}

Ley $1 / 2005$, de 9 de marzo, por la que se regula el régimen del comercio de derechos de emisión de gases de efecto invernadero (BOE $n$. ${ }^{\circ}$ 59 , de 10 de marzo); Ley 2/2005, de 15 de marzo, por la que se adoptan medidas urgentes para reparar los daños causados por los incendios e inundaciones acaecidos en las Comunidades Autónomas de Aragón, Cataluña, Andalucía, La Rioja, Comunidad Foral de Navarra y Comunidad Valenciana (BOE n. ${ }^{\circ}$ 64, de 16 de marzo); Ley 3/2005, de 18 de marzo, por la que se reconoce una prestación económica a los ciudadanos de origen español desplazados al extranjero, durante su minoría de edad, como consecuencia de la Guerra Civil, y que desarrollaron la mayor parte de su vida fuera del territorio nacional (BOE n. ${ }^{\circ} 68$, de 21 de marzo; corrección de erratas en BOE n. ${ }^{\circ} 80$, de 4 de abril); Ley 4/2005, de 22 de abril, sobre efectos en las pensiones no contributivas de los complementos otorgados por las Comunidades Autónomas (BOE n. ${ }^{\circ}$ 97, de 23 de abril); Ley $5 / 2005$, de 22 de abril, de supervisión de los conglomerados financieros y por la que se modifican otras leyes del sector financiero (BOE n. ${ }^{\circ} 97$, de 23 de abril); Ley 6/2005, de 22 de abril, sobre saneamiento y liquidación de las entidades de crédito (BOE $n .^{\circ} 97$, de 23 de abril); Ley 7/2005, de 13 de mayo, por la que se crea el Consejo General de Colegios Oficiales de Psicólogos (BOE n. ${ }^{\circ} 115$, de 14 de mayo); Ley 8/2005, de 6 de junio, para compatibilizar las pensiones de invalidez en su modalidad no contributiva con el trabajo remunerado (BOE n. ${ }^{\circ} 135$, de 7 de junio); Ley 9/2005, de 6 de junio, para compatibilizar las pensiones del Seguro Obligatorio de Vejez e Invalidez (SOVI) con las pensiones de viudedad del sistema de la Seguridad Social (BOE n. ${ }^{\circ}$ 135, de 7 de junio); Ley 10/2005, de 14 de junio, de Medidas Urgentes para el Impulso de la Televisión Digital Te- 
rrestre, de Liberalización de la Televisión por Cable y de Fomento del Pluralismo (BOE n. ${ }^{\circ} 142$, de 15 de junio); Ley 11/2005, de 22 de junio, por la que se modifica la Ley 10/2001, de 5 de julio, del Plan Hidrológico Nacional (BOE n. ${ }^{\circ} 149$ de 23 de junio); Ley 12/2005, de 22 de junio, por la que se modifica el artículo 23 de la Ley de 8 de junio de 1957, del Registro Civil (BOE n. ${ }^{\circ} 149$ de 23 de junio); Ley 13/2005, de 1 de julio, por la que se modifica el Código Civil en materia de derecho a contraer matrimonio (BOE n. ${ }^{\circ} 157$, de 2 de julio); Ley 14/2005, sobre las cláusulas de los Convenios Colectivos referidas al cumplimiento de la edad ordinaria de jubilación (BOE n. ${ }^{\circ} 157$, de 2 de julio); Ley 15/2005, de 8 de julio, por la que se modifican el Código Civil y la Ley de Enjuiciamiento Civil en materia de separación y divorcio (BOE n. ${ }^{\circ} 163$, de 9 de julio); Ley 16/2005, de 18 de julio, por la que se modifica la Ley 1/1996, de 10 de enero, de asistencia jurídica gratuita, para regular las especialidades de los litigios transfronterizos civiles y mercantiles en la Unión Europea (BOE n. ${ }^{\circ}$ 171, de 19 de julio); Ley 17/2005, de 19 de julio, por la que se regula el permiso y la licencia de conducción por puntos y se modifica el texto articulado de la ley sobre tráfico, circulación de vehículos a motor y seguridad vial (BOE n. ${ }^{172}$, de 20 de julio); Ley 18/2005, de 30 de septiembre, por la que se deroga la Ley 23/1986, de 24 de diciembre, por la que se establecen las bases del régimen jurídico de las Cámaras Agrarias (BOE n. ${ }^{\circ}$ 235, de 1 de octubre); Ley 19/2005, de 14 de noviembre, sobre la sociedad anónima europea domiciliada en España (BOE n. ${ }^{\circ} 273$, de 15 de noviembre); Ley 20/2005, de 14 de noviembre, sobre la creación del Registro de Contratos de Seguros de cobertura de fallecimiento (BOE n. ${ }^{\circ} 273$, de 15 de noviembre); Ley 21/2005, de 17 de noviembre, de restitución a la Generalidad de Cataluña de los documentos incautados con motivo de la Guerra Civil custodiados en el Archivo General de la Guerra Civil Española y de creación del Centro Documental de la Memoria Histórica (BOE n. ${ }^{\circ} 276$, de 18 de noviembre); Ley 22/2005, de 18 de noviembre, por la que se incorporan al ordenamiento jurídico español diversas directivas comunitarias en materia de fiscalidad de productos energéticos y electricidad y del régimen fiscal común aplicable a las sociedades matrices y filiales de estados miembros diferentes, y se regula el régimen fiscal de las aportaciones transfronterizas a fondos de pensiones en el ámbito de la Unión Europea (BOE n. ${ }^{\circ} 277$, de 19 de noviembre); Ley 23/2005, de 18 de noviembre, de reformas en materia tributaria para el impulso a la productividad (BOE n. ${ }^{\circ} 277$, de 19 de noviembre); Ley 24/2005, de 18 de noviembre, de reformas para el impulso a la productividad (BOE n. ${ }^{\circ} 277$, de 19 de noviembre); Ley 25/2005, de 24 de noviembre, reguladora de las entidades de capital-riesgo y sus sociedades gestoras (BOE n. ${ }^{\circ} 282$, de 25 de noviembre); Ley 26/2005, de 30 de noviembre, por la que se modifica la Ley 49/2003, de 26 de noviembre, de Arrendamientos Rústicos (BOE n. ${ }^{\circ}$ 287 , de 1 de diciembre); Ley 27/2005, de 30 de noviembre, de fomento de la educación y la cultura de la paz (BOE n. ${ }^{\circ} 287$, de 1 de diciembre); Ley $28 / 2005$, de 26 de diciembre, de medidas sanitarias frente al tabaquismo y reguladora de la venta, el suministro, el consumo y la publicidad de los 
productos del tabaco (BOE n. ${ }^{\circ} 309$, de 27 de diciembre); Ley 29/2005, de 29 de diciembre, de Publicidad y Comunicación Institucional (BOE n. ${ }^{\circ}$ 312 , de 30 de diciembre).

Finalmente, en lo que a los Presupuestos del Estado se refiere, se aprobó la Ley 30/2005, de 29 de diciembre, de Presupuestos Generales del Estado para el año 2006 (BOE n. ${ }^{\circ}$ 312, de 30 de diciembre).

En el ámbito autonómico, deben mencionarse las siguientes Leyes presupuestarias:

Ley $16 / 2005$, de 28 de diciembre, del Presupuesto de la Comunidad Autónoma de Andalucía para el año 2006 (BOJA n. ${ }^{\circ}$ 254, de 31 de diciembre); Ley 12/20050, de 30 de diciembre, de Presupuestos de la Comunidad Autónoma de Aragón para el año 2006 (BOA n. ${ }^{\circ}$ 154, de 31 de diciembre); Ley 9/2005, de 27 de diciembre, de Presupuestos Generales de la Comunidad Autónoma de Canarias para 2006 (BOCA n. ${ }^{\circ} 255$, de 30 de diciembre); Ley 5/2005, de 26 de diciembre, de Presupuestos Generales de la Comunidad Autónoma de Cantabria para el año 2006 (BOC n. ${ }^{\circ}$ 252, de 30 de diciembre); Ley 14/2005, de 27 de diciembre, de Presupuestos Generales de la Comunidad de Castilla y León para 2006 (BOCL n. ${ }^{\circ} 250$, de 29 de diciembre); Ley 13/2005, de 29 de diciembre, de Presupuestos Generales de la Junta de Comunidades de Castilla-La Mancha para 2006 (DOCM n. ${ }^{\circ} 264$ ); Ley 20/2005, de 29 de diciembre, de presupuestos de la Generalidad de Cataluña para 2006 (DOGC n. ${ }^{\circ} 4541$, de 31 de diciembre); Ley 5/2005, de 27 de diciembre, de Presupuestos Generales de la Comunidad Autónoma de Extremadura para 2006 (DOE extraordinario $n .^{\circ} 5$, de 30 de diciembre); Ley $7 / 2005$, de 29 de diciembre, de Presupuestos generales de la Comunidad Autónoma de Galicia para el año 2006 (DOG n. ${ }^{\circ}$ 250, de 30 de diciembre); Ley 12/2005, de 27 de diciembre, de Presupuestos generales de la Comunidad Autónoma de las Illes Balears para el año 2006 (BOIB n. ${ }^{\circ}$ 196, de 31 de diciembre); Ley 12/2005, de 16 de diciembre, de Presupuestos Generales de la Comunidad Autónoma de La Rioja para el año 2006 (BOR n. ${ }^{\circ}$ 170, de 27 de diciembre); Ley 6/2005, de 23 de diciembre, de Presupuestos generales de la Comunidad de Madrid para 2006 (BOCM n. ${ }^{\circ} 211$, de 30 de diciembre); Ley Foral 18/2005, de 29 de diciembre, de Presupuestos generales de Navarra para el ejercicio 2006 (BON n. ${ }^{\circ} 156$, de 30 de diciembre); Ley $5 / 2005$, de 29 de diciembre, por la que se aprueban los Presupuestos generales de la Comunidad Autónoma de Euskadi para el ejercicio 2005 (BOPV n. ${ }^{\circ}$ 249, de 31 de diciembre); Ley 6/2005, de 29 de diciembre, de Presupuestos generales del Principado de Asturias para 2006 (BOPA n. ${ }^{\circ}$ 301, de 31 de diciembre); Ley 10/2005, de 29 de diciembre, de Presupuestos Generales de la Comunidad Autónoma de la Región de Murcia para el ejercicio 2006 (BORM n..$^{\circ} 301$, de 31 de diciembre) y Ley 15/2005, de 26 de diciembre, de Presupuestos de la Generalitat Valenciana para el ejercicio 2006 (DOGV n. ${ }^{\circ}$ 5166, de 30 de diciembre). 
A propósito de los Órganos Auxilares de las Cortes Generales, el Defensor del Pueblo presentó el 20 de abril, ante la Comisión Mixta para las Relaciones con el Defensor del Pueblo, el Informe correspondiente al año $2004^{10}$ en el que se reseña, entre otras cosas, lo siguiente:

En el año 2004 se registraron un total de 28.990 quejas. Se contabilizan todas, tanto las que se reciben de modo externo como los que se incoan de oficio por la propia Institución. Ha sido importante el incremento de las quejas colectivas, que han pasado de 4.612 a 14.614 , y muy significativo el de las quejas individuales, que han pasado de 12.612 en el año 2003 a 14.264 en el 2004. El número de quejas recibidas de mujeres casi se ha duplicado, cosa que no ha ocurrido con las provenientes de hombres; pese a todo, sigue existiendo una diferencia notable de más de 3.000 quejas favorable a los varones.

Tomando en consideración las quejas individuales, a efectos de una mayor representatividad, el número mayor de quejas recibidas se observa en las relativas a la Administración de justicia, seguidas de las concernientes a Ordenación de la actividad económica. Por lo que se refiere a las colectivas, el mayor número lo encontramos en Administración educativa, motivado por la queja relativa a la titulación en psicología, como se verá en el apartado correspondiente.

Constituyen las quejas de oficio más numerosas las relativas a los derechos del interno en prisión y su tutela por la Administración penitenciaria.

Del conjunto de 28.990 quejas recibidas durante 2004, el Defensor del Pueblo destacó las 8.953 recibidas sobre temas relacionados con la Educación, 3.446 con la Economía, 2.349 con la Administración de Justicia, 2.183 con la Inmigración y más de 2.000 con el Empleo Público.

El estado de tramitación de las 28.990 quejas registradas, a finales del ejercicio, es el siguiente: 9.507 habían sido admitidas a trámite; 16.846 no habían sido admitidas, y 2.637 se encontraban pendientes de tomar una decisión al respecto. Entre las admitidas, se comprenden 3.880 concluidas, 5.600 en trámite y 27 en suspenso. De las recomendaciones y sugerencias emitidas a distintas Administraciones públicas se han admitido 169 , rechazado 82 y 56 están pendientes de respuesta por las administraciones correspondientes. Por tanto, de las 251 respuestas recibidas por las Administraciones, fueron admitidas mas del 67 por ciento.

Además, el Defensor del Pueblo presentó 3 Informes monográficos: el 8 de marzo, el estudio "Contaminación acústica»; el 22 de noviembre, el estudio «Informe sobre asistencia jurídica a los extranjeros en Espa-

10 Disponible en http://www.defensordelpueblo.es/informes1.asp 
ña», y el 22 de diciembre, el estudio monográfico "Daño cerebral sobrevenido en España: un acercamiento epidemiológico y sociosanitario»" ${ }^{11}$.

Enrique Múgica Herzog resultó reelegido como Defensor del Pueblo el 30 de junio de 2005; en el Pleno del Congreso de los Diputados obtuvo 252 votos a favor, 18 en contra y 19 en blanco; en el Pleno del Senado contó con 174 votos a favor, 11 en contra y 26 en blanco (el nombramiento apareció en el BOE n. ${ }^{\circ} 155$, de 30 de junio).

En Asturias se aprobó la Ley 5/2005, de 16 de diciembre, del Procurador General (BOPA n. ${ }^{\circ} 300$, de 30 de diciembre).

En lo que respecta a otro de los órganos auxiliares, el Tribunal de Cuentas, como ya se ha dicho, aprobó, en sesión celebrada el 27 de octubre de 2005, el Informe de Fiscalización de la Contabilidad de los Partidos Políticos del ejercicio 2002 y acordó la elevación de dicho Informe a las Cortes Generales ${ }^{12}$.

El Gobierno de la Nación aprobó, en el Consejo de Ministros de 22 de julio, el Acuerdo sobre las Directrices de técnica normativa (BOE n. ${ }^{\circ}$ 180, de 29 de julio)

Por lo que a su actividad legislativa se refiere, se aprobaron 16 Decretos-Ley:

Real Decreto-Ley $1 / 2005$, de 4 de febrero, por el que se adoptan medidas urgentes para paliar los daños ocasionados en el sector agrario por las heladas acaecidas en el mes de enero de 2005 (BOE n. ${ }^{\circ} 34$, de 9 de febrero; corrección de errores: $\mathrm{BOE} n$. $^{\circ} 59$, de 10 de marzo; convalidación: 10 de marzo, BOE, n. ${ }^{\circ}$ 64, de 16 de marzo); Real Decreto-Ley 2/2005, de 11 de febrero, por el que se adoptan medidas urgentes para reparar los daños causados por los movimientos sísmicos acaecidos el 29 de enero y los primeros días del mes de febrero de 2005 en Lorca (Murcia) (BOE n. ${ }^{\circ} 37$, de 12 de febrero; convalidación: 10 de marzo, BOE n. ${ }^{\circ} 64$, de 16 de marzo); Real Decreto-Ley 3/2005, de 18 de febrero, por el que se adoptan medidas en relación con la prestación de servicios portuarios básicos y se amplía el plazo para la transformación de las sociedades estatales de estiba y desestiba en agrupaciones portuarias de interés económico (BOE n. ${ }^{\circ} 43$, de 19 de febrero; convalidación: 10 de marzo, BOE n. ${ }^{\circ} 64$, de 16 de marzo); Real Decreto-Ley 4/2005, de 11 de marzo, por el que se concede un plazo extraordinario de solicitud de ayudas para las víctimas del terrorismo (BOE n. ${ }^{\circ}$ 61, de 12 de marzo; convalidación: 7 de abril, BOE n. ${ }^{\circ} 89$, de 14 de abril); Real Decreto-Ley 5/2005, de 11 de marzo, de re-

11 Pueden consultarse en http://www.defensordelpueblo.es/informes2.asp

12 El Informe puede consultarse en http://www.tcu.es 
formas urgentes para el impulso a la productividad y para la mejora de la contratación pública (BOE n. ${ }^{\circ}$ 62, de 14 de marzo; convalidación: 7 de abril, BOE, n. ${ }^{\circ} 89$, de 14 de abril); Real Decreto-Ley 6/2005, de 8 de abril, por el que se establece la aplicación del Real Decreto Ley 1/2005, de 4 de febrero, por el que se adoptan medidas urgentes para paliar los daños ocasionados en el sector agrario por las heladas acaecidas en el mes de enero de 2005, a los daños ocasionados por las heladas acaecidas durante los meses de febrero y marzo de 2005 (BOE n. ${ }^{\circ}$ 87, de 12 de abril; convalidación: 7 de abril, BOE n. ${ }^{\circ} 109$, de 7 de mayo); Real Decreto-Ley $7 / 2005$, de 22 de abril, por el que se modifica la Ley $2 / 2004$, de 27 de diciembre, de Presupuestos Generales del Estado para el año 2005, en materia de financiación de la formación continua (BOE n. ${ }^{\circ} 99$, de 26 de abril; convalidación: 19 de mayo, BOE n. ${ }^{\circ} 126$, de 27 de mayo); Real Decreto-Ley $8 / 2005$, de 27 de mayo, por el que se adoptan medidas urgentes para reparar los daños causados por las inundaciones acaecidas en la isla de La Gomera (BOE n. ${ }^{\circ} 127$, de 28 de mayo; convalidación: 23 de junio, BOE n. ${ }^{\circ}$ 155, de 30 de junio); Real Decreto-Ley 9/2005, de 6 de junio, por el que se prorroga el plazo previsto en la disposición transitoria quinta de la Ley Orgánica 6/2001, de 21 de diciembre, de Universidades, para la renovación de los contratos de los profesores asociados contratados conforme a la legislación anterior (BOE $n .^{\circ} 135$, de 7 de junio; convalidación: 23 de junio, BOE n. ${ }^{\circ}$ 155, de 30 de junio); Real Decreto-Ley $10 / 2005$, de 20 de junio, por el que se adoptan medidas urgentes para paliar los daños producidos en el sector agrario por la sequía y otras adversidades climáticas (BOE n. ${ }^{\circ} 147$, de 21 de junio; corrección de errores: BOE n. ${ }^{\circ} 151$, de 25 de junio; convalidación: 29 de junio, BOE n. ${ }^{\circ} 161$, de 7 de julio); Real Decreto-Ley 11/2005, de 22 de julio, por el que se aprueban medidas urgentes en materia de incendios forestales (BOE n. ${ }^{\circ} 175$, de 23 de julio; corrección de errores: BOE n. ${ }^{\circ} 178$, de 27 de julio y BOE n. ${ }^{\circ} 179$, de 28 de julio; convalidación: 28 de julio, BOE n. ${ }^{\circ} 184$, de 3 de agosto); Real Decreto-Ley 12/2005, de 16 de septiembre, por el que se aprueban determinadas medidas urgentes en materia de financiación sanitaria (BOE n. ${ }^{\circ} 223$, de 17 de septiembre; convalidación: 29 de septiembre, BOE n. ${ }^{\circ} 240$, de 7 de octubre); Real Decreto-Ley 13/2005, de 28 de octubre, por el que se modifica la Ley 4/1986, de 8 de enero, de cesión de bienes del patrimonio sindical acumulado (BOE n. ${ }^{\circ} 263$, de 3 de noviembre; convalidación: 24 de noviembre, $\mathrm{BOE}$ n. ${ }^{\circ} 287$, de 1 de diciembre); Real Decreto-Ley 14/2005, de 2 de diciembre, por el que se adoptan medidas urgentes para reparar los daños causados por la tormenta tropical Delta en el archipiélago canario los días 28 y 29 de noviembre (BOE n. ${ }^{\circ} 291$, de 6 de diciembre; convalidación: 15 de diciembre, BOE n. ${ }^{\circ} 305$, de 22 de diciembre); Real Decreto-Ley 15/2005, de 16 de diciembre, de medidas urgentes para la regulación de las transacciones de derechos al aprovechamiento de agua (BOE n. ${ }^{\circ}$ 301, de 17 de diciembre; convalidación: 22 de diciembre, BOE n. ${ }^{\circ} 311$, de 29 de diciembre); Real Decreto-Ley $16 / 2005$, de 30 de diciembre, por el que se modifica el régimen transitorio de adaptación de las comisiones de control de los planes de pensiones 
de empleo y se regula la adaptación de determinados compromisos por pensiones vinculados a la jubilación (BOE n. ${ }^{\circ}$ 313, de 31 de diciembre de 2005).

En el ámbito de la Administración General del Estado se aprobó la Ley 29/2005, de 29 de diciembre, de Publicidad y Comunicación Institucional (BOE n. ${ }^{\circ} 312$, de 30 de diciembre), cuyos objetivos vienen resumidos en la Exposición de Motivos:

"La Ley regula el contenido de los mensajes difundidos a través de campañas de publicidad y de comunicación, dispone garantías frente a aquellas que incumplan sus mandatos y establece mecanismos de planificación, coordinación y control de la actividad de publicidad y de comunicación institucional que desarrolla la Administración General del Estado. Asimismo, la Ley tiene como objetivos prioritarios garantizar la utilidad pública, la profesionalización, la transparencia y la lealtad institucional en el desarrollo de las campañas institucionales de publicidad y de comunicación. La utilidad pública como objetivo de estas campañas implica la erradicación de aquellas que tengan como finalidad ensalzar la labor del Gobierno. Se garantiza así que las campañas sirvan a sus destinatarios legítimos, que son los ciudadanos, y no a quien las promueve. Además, la Ley otorga prioridad a este objetivo ampliando el número de receptores potenciales incorporando previsiones tendentes a garantizar la accesibilidad de las personas con discapacidad y edad avanzada a los contenidos de la publicidad institucional que se realicen y difundan en soporte audiovisual y la pluralidad lingüística de las campañas. El segundo objetivo pasa por profesionalizar la planificación, ejecución y evaluación de las campañas, para asegurar el máximo aprovechamiento de los recursos públicos. Con el tercer objetivo se fortalece la transparencia de las campañas, mediante la habilitación de fórmulas que den a conocer todas las actividades de publicidad y de comunicación que prevea desarrollar la Administración General del Estado, incluidas las de las entidades que le están adscritas. Finalmente, el cuarto objetivo implica velar por la lealtad institucional; con este fin, se prohíben las campañas destinadas a denostar la actividad de otras Administraciones en el uso legítimo de sus competencias. Teniendo en cuenta la duración en que se desarrollan habitualmente las campañas institucionales de publicidad y de comunicación, la eficacia de la garantía de los intereses y derechos de los ciudadanos precisa de un sistema ágil de control. Con este fin se articula un procedimiento administrativo de carácter especial y sumario que permite a los ciudadanos solicitar la cesación o la rectificación de la actividad contraria a las prohibiciones dispuestas por la Ley. Se atribuye a una Comisión de publicidad y comunicación institucional, adscrita al Ministerio de la Presidencia, la competencia para conocer de este tipo de solicitudes. La realización de las campañas institucionales de publicidad y de comunicación debe responder a los principios de eficacia, 
transparencia, austeridad y eficiencia, para lo cual se crean fórmulas orgánicas y de actuación administrativa que aseguren la coordinación entre los distintos departamentos ministeriales. Se ordena, en fin, la elaboración de un informe anual en el que se incluirán todas las campañas contratadas por la Administración General del Estado y la relación de los adjudicatarios de los contratos celebrados, que será remitido a las Cortes Generales".

Además, debe citarse el Real Decreto 951/2005, de 29 de julio, por el que se establece el marco general para la mejora de la calidad en la Administración General del Estado (BOE n. ${ }^{\circ} 211$, de 3 de septiembre).

En lo que se refiere a la Administración militar, ha de hacerse una somera mención al contenido de la Ley Orgánica 5/2005, de 17 de noviembre, de la Defensa Nacional (BOE n. ${ }^{\circ} 276$, de 18 de noviembre); en su articulado se establecen, entre otras cosas, las siguientes:

Al Congreso de los Diputados le corresponde autorizar, con carácter previo, la participación de las Fuerzas Armadas en misiones fuera del territorio nacional, de acuerdo con lo establecido en esta Ley, lo que significa que para ordenar operaciones en el exterior que no estén directamente relacionadas con la defensa de España o del interés nacional, el Gobierno realizará una consulta previa y recabará la autorización del Congreso de los Diputados. En las misiones en el exterior que, de acuerdo con compromisos internacionales, requieran una respuesta rápida o inmediata a determinadas situaciones, los trámites de consulta previa y autorización se realizarán mediante procedimientos de urgencia que permitan cumplir con dichos compromisos. Cuando por razones de máxima urgencia no fuera posible realizar la consulta previa, el Gobierno someterá al Congreso de los Diputados lo antes posible la decisión que haya adoptado para la ratificación, en su caso.

Corresponde al Gobierno determinar la política de defensa y asegurar su ejecución, así como dirigir la Administración militar y acordar la participación de las Fuerzas Armadas en misiones fuera del territorio nacional.

Las Fuerzas Armadas se organizan en dos estructuras: una orgánica, para la preparación de la fuerza, y otra operativa, para su empleo en las misiones que se le asignen. La estructura orgánica posibilitará la generación de la estructura operativa. Se establecerá mediante criterios de funcionalidad basados en los medios y formas propias de acción del Ejército de Tierra, de la Armada y del Ejército del Aire, y en una organización homogénea de éstos. La estructura operativa, establecida para el desarrollo de la acción conjunta y combinada, se organizará con arreglo al principio de unidad de mando y a los criterios necesarios para la consecución de la máxima capacidad operativa. 
Quedan prohibidos los Tribunales de Honor en el ámbito militar.

El Gobierno, en el plazo de tres meses, deberá remitir al Congreso de los Diputados un proyecto de ley reguladora de los derechos fundamentales de los militares profesionales, que incluirá la creación del Observatorio de la vida militar.

Además, han de citarse el Real Decreto 890/2005, de 22 de julio, por el que se modifica el Reglamento de evaluaciones y ascensos del personal militar profesional, aprobado por el Real Decreto 1064/2001, de 28 de septiembre (BOE n. ${ }^{\circ} 215$, de 8 de septiembre) y el Real Decreto $1314 / 2005$, de 4 de noviembre, por el que se aprueba el Reglamento de retribuciones del personal de las Fuerzas Armadas (BOE n. ${ }^{2} 265$, de 5 de noviembre).

En el ámbito de los Gobiernos autonómicos, tras las elecciones parlamentarias vascas y gallegas antes mencionadas, Juan José Ibarretxe fue elegido Lehendakari con los votos favorables de PNV (22), EA (7), EB (3) y EHAK (2), y Emilio Pérez Touriño fue elegido Presidente de la Xunta de Galicia con los votos de PSG-PSOE (25) y BNG (13).

En este sector, ha de recordarse la aprobación de las siguientes leyes:

En Andalucía, la Ley 2/2005, de 8 de abril, por la que se regula el Estatuto de los ex Presidentes de la Junta de Andalucía (BOPA n. ${ }^{\circ} 74$, de 18 de abril); la Ley $3 / 2005$, de 8 de abril, de incompatibilidades de Altos Cargos de la Administración de la Junta de Andalucía y de Declaración de Actividades, Bienes e Intereses de Altos Cargos y otros Cargos Públicos (BOPA n. ${ }^{\circ} 74$, de 18 de abril), y la Ley 6/2005, de 8 de abril, reguladora de la actividad publicitaria de las Administraciones Públicas de Andalucía (BOPA n. ${ }^{\circ} 74$, de 18 de abril); en Castilla y León, la Ley 7/2005, de 24 de mayo, de la Función Pública de Castilla y León (BOCL n. ${ }^{\circ} 103$, de 31 de mayo) y la Ley 12/2005, de 27 de diciembre, reguladora del Estatuto de los ex Presidentes de la Junta de Castilla y León (BOCL, suplemento n. ${ }^{\circ} 1$ al n. ${ }^{\circ}$ 249, de 28 de diciembre); en Cataluña, la Ley 1/2005, de 31 de marzo, del consejero o consejera primero del Gobierno de la Generalitat (DOGC n. ${ }^{\circ} 4355$, de 4 de abril); la Ley 5/2005, de 2 de mayo, de la Comisión Jurídica Asesora (DOGC n. ${ }^{\circ} 4379$, de 6 de mayo); y la Ley 9/2005, de 7de julio, del Jurado de Expropiación de Cataluña (DOGC n. ${ }^{\circ} 427$, de 15 de julio); en Navarra, la Ley Foral 21/2005, de 29 de diciembre, de evaluación de las políticas públicas y de la calidad de los servicios públicos (BON n. ${ }^{\circ} 4$, de 9 de enero de 2006); en la Región de Murcia, la Ley 6/2004, de 28 de diciembre, del Estatuto del Presidente y del Consejo de Gobierno de la Región de Murcia (BORM, suplemento n. ${ }^{\circ} 11$, de 30 de diciembre de 2004); la Ley 7/2004, de 28 de diciembre, de organización y régimen jurídico de la Administración Pública de la Comunidad Autónoma de la 
Región de Murcia (BORM, suplemento n. ${ }^{\circ} 11$, de 30 de diciembre de 2004); en la Comunidad Valenciana, la Ley 10/2005, de 9 de diciembre, de asistencia jurídica a la Generalitat (DOGV n. ${ }^{\circ}$ 5152, de 12 de diciembre de 2005), y en La Rioja, la Ley 4/2005, de 1 de junio, de Funcionamiento y Régimen Jurídico de la Administración de la Comunidad Autónoma de La Rioja (BOR n. ${ }^{\circ} 76$, de 7 de junio).

Respecto de los órganos consultivos, se aprobaron:

El Real Decreto 449/2005, de 22 de abril, por el que se modifica el Reglamento Orgánico del Consejo de Estado, aprobado por el Real Decreto 1674/1980, de 18 de julio (BOE n. ${ }^{\circ} 99$, de 26 de abril); en el ámbito autonómico, la Ley 4/2005, de 8 de abril, del Consejo Consultivo de Andalucía (BOPA, n. ${ }^{\circ} 74$, de 18 de abril); la Ley 2/2005, de 20 de mayo, de modificación de la Disposición Transitoria Segunda de la Ley 1/2004, de 21 de octubre del Consejo Consultivo del Principado de Asturias (BOPA n. ${ }^{\circ} 118$, de 24 de mayo), por la que se fija el 2 de noviembre de 2005 como fecha a partir de la que empezará a ejercer su función consultiva; la Ley 7/2005, de 8 de junio, del Consejo de Trabajo, Económico y Social de Cataluña (DOGC n. ${ }^{\circ} 4407$, de 16 de junio); la Ley $5 / 2005$, de 5 de agosto, de creación del Consell Jurídic Consultiu de la Comunitat Valenciana (DOGV n. ${ }^{\circ}$ 5067, de 9 de agosto), y la Ley 10/2005, de 30 de septiembre, por la que se modifica parcialmente la Ley 6/1997, de 18 de julio, reguladora del Consejo Económico y Social de La Rioja (BOLR n. ${ }^{\circ}$ 132, de 6 de octubre).

En lo que se respecta al Poder Judicial y a la Administración de Justicia, han de mencionarse el Real Decreto 796/2005, de 1 de julio, por el que se aprueba el Reglamento general de régimen disciplinario del personal al servicio de la Administración de Justicia (BOE n. ${ }^{\circ}$ 175, de 23 de julio) y el Acuerdo de 15 de septiembre del Pleno del Consejo General del Poder Judicial por el que se aprueba el Reglamento 1/2005, de los aspectos accesorios de las actuaciones judiciales (BOE n. ${ }^{\circ} 231$, de 27 de septiembre).

Por lo que al Tribunal Constitucional se refiere, y en relación con el control de constitucionalidad, han de mencionarse las siguientes sentencias ${ }^{13}$ :

La STC 10/2005, de 20 de enero, resolvió las cuestiones de inconstitucionalidad acumuladas, planteadas todas ellas por la Sección Primera de la Sala de lo Contencioso-Administrativo del Tribunal Superior de Justicia de Cataluña, sobre el artículo 9.7 del Decreto 3313/1966, de 29 de diciembre, por el que se aprueba el texto refundido de la Ley del

${ }_{13}$ Pueden verse en http://www.tribunalconstitucional.es/JC.htm 
impuesto sobre actividades y beneficios comerciales e industriales, por presunta vulneración de los artículos 14, 31.1, 38 y 133.3 de la Constitución; y alternativa o subsidiariamente sobre el artículo 279.7 y disposición derogatoria, apartado 1, disposición undécima, del Real Decreto Legislativo 781/1986, de 18 de abril, por el que se aprueba el texto refundido de las disposiciones legales vigentes en materia de régimen local, por presunta vulneración del artículo 82.5 y 6 de la Constitución.

El Tribunal resolvió que el artículo 9.7 del Decreto 3313/1966 por el que se aprueba el texto refundido de la Ley del impuesto sobre actividades y beneficios comerciales e industriales, es contrario a la Constitución sólo en la medida en que es aplicable a la parte mercantil de las cajas de ahorro y, por tanto, no se limita - como expresamente señalaría luego el artículo 24.1 de la Ley 40/1981, de 28 de octubre- "a los Montes de Piedad y Obras Benéfico-Sociales de las Cajas expresamente autorizadas». Siendo inconstitucional la disposición cuestionada en los términos citados, por vulnerar el principio constitucional de contribuir a los gastos públicos en términos de igualdad (arts. 14 y $31.1 \mathrm{CE}$ ), resulta innecesario entrar a conocer de las restantes vulneraciones que el órgano judicial imputa a la norma cuestionada. En suma, se declara inconstitucional y derogado por la Constitución el artículo 9.7 del Decreto 3313/1966.

La STC 48/2005, de 3 de marzo, se pronunció sobre la cuestión de inconstitucionalidad, promovida por la Sala de lo Contencioso-Administrativo del Tribunal Superior de Justicia de Canarias, en relación con la Ley del Parlamento de Canarias 2/1992, de 26 de junio, sobre declaración de utilidad pública de la expropiación forzosa de los edificios núm. 5 de la calle Teobaldo Power y núms. 44 y 46 de la calle del Castillo, en Santa Cruz de Tenerife, para proceder a la ampliación de la sede del Parlamento de Canarias, por supuesta vulneración del artículo 33.3.

Concluyó el Tribunal que «ni la exposición de motivos de la Ley canaria 2/1992 ni su propio articulado explicitan en modo alguno los motivos por los que los bienes cuya necesidad de ocupación se acuerda de manera directa por el legislador autonómico son más idóneos o adecuados para materializar la causa expropriandi que aquellos otros bienes colindantes cuya expropiación se difiere hacia el futuro por el artículo 2 de la Ley autonómica cuestionada, y respecto a los cuales, además, se prevé que será el Gobierno Canario -y no la Cámara legislativa autonómica- quien acuerde la necesidad de su ocupación, ampliándose de este modo el abanico de eventuales medios de impugnación de tal decisión administrativa, de los que no se beneficiarán, obviamente, los propietarios de los directamente expropiados por el legislador. Por ello, estimar parcialmente la cuestión de inconstitucionalidad y, en su virtud, 
declara inconstitucional y nulo el artículo primero de la Ley canaria 2/1992, de 26 de junio.

La STC 102/2005, de 20 de abril, se ocupó de la cuestión de inconstitucionalidad planteada por la Sección Segunda de la Sala de lo Contencioso-Administrativo del Tribunal Supremo sobre los apartados $1 \mathrm{y}$ 2 del artículo 70 de la Ley 27/1992, de 24 de noviembre, de puertos del Estado y de la marina mercante, por posible vulneración del artículo 31.3 de la Constitución.

El Tribunal recuerda que la determinación en la ley de un límite máximo de la prestación de carácter público, o de los criterios para fijarlo, es absolutamente necesaria para respetar el principio de reserva de ley. Esa determinación no aparece en el precepto cuestionado, que, al señalar que será el Ministro de Obras Públicas y Transportes el que establecerá "los límites mínimos y máximos de las tarifas", traza un ámbito de cuantificación que deja un amplísimo margen de libertad al mencionado órgano del poder ejecutivo, lo que implica una habilitación tan indeterminada que desborda los límites que para la colaboración reglamentaria derivan de las exigencias de la reserva de ley establecida en los arts. 31.3 y 133.1 CE. Procede, en consecuencia, declarar inconstitucional el apartado 2 del artículo 70 de la Ley 27/1992, de 24 de noviembre, de puertos del Estado y de la marina mercante, en su versión original, en la medida en que se aplica a prestaciones patrimoniales de carácter público. Esta declaración de inconstitucionalidad debe extenderse también al apartado 1 del mismo precepto legal, en tanto que califica como "precios privados" los que constituyen verdaderas "prestaciones patrimoniales de carácter público" a las que hace referencia el artículo 31.3 CE.

En el mismo sentido se pronunció la STC 121/2005, de 10 de mayo.

La STC 138/2005, de 26 de mayo, estimó la cuestión de inconstitucionalidad planteada por el Juzgado de Primera Instancia núm. 17 de Madrid, sobre supuesta inconstitucionalidad del párrafo primero del artículo 136 del Código Civil en relación con los arts. 14, 24.1 y 39.2 de la Constitución, declarándolo inconstitucional en cuanto comporta que el plazo para el ejercicio de la acción de impugnación de la paternidad matrimonial empiece a correr aunque el marido ignore que no es el progenitor biológico de quien ha sido inscrito como hijo suyo en el Registro Civil. Esta decisión se reprodujo en la STC 156/2005, de 9 de junio.

La STC 155/2005, de 9 de junio, resolvió los recursos de inconstitucionalidad acumulados promovidos por más de cincuenta Diputados del Grupo Parlamentario Socialista del Congreso contra el Real Decre- 
to-ley 14/1998, de 9 de octubre, de adhesión de España a diversos Acuerdos del Fondo Monetario Internacional y, en especial, contra los arts. 2 y 3, y contra la Ley 13/1999, de 21 de abril, de adhesión de España a diversos Acuerdos del Fondo Monetario Internacional y, en especial, contra los arts. 2 y 3.

Para el Tribunal, es evidente que el decreto-ley no es una forma jurídica habilitada para la autorización requerida por el artículo 94.1 CE. De un lado, porque el artículo 86.1 CE sólo prevé la figura del decreto-ley para el dictado de "disposiciones legislativas", categoría jurídica que es distinta de la que corresponde a las autorizaciones, por lo que no puede considerarse instrumento idóneo para el acuerdo de autorizaciones. De otro, porque tratándose de una autorización es claro que no puede concederla quien debe ser autorizado. Por último, porque el decreto-ley es una fuente normativa propia del Gobierno que sólo precisa de la intervención del Congreso de los Diputados - y no de las dos Cámaras que integran las Cortes Generales- para la estabilización de su vigencia en el Ordenamiento. Por ello ni siquiera tras su convalidación parlamentaria es el decreto-ley una forma jurídica capaz de dispensar una autorización que sólo pueden brindar las Cortes Generales, pues la convalidación del Congreso de los Diputados nunca puede ser la del órgano complejo en el que se integra junto con el Senado, de manera que no es posible ver en la convalidación un acto equivalente a la autorización requerida por el artículo 94.1 CE.

En consecuencia, el artículo 2 del Real Decreto-ley 14/1998 es inconstitucional por infracción del artículo 94.1 d) de la Constitución. Igualmente es apreciable la inconstitucionalidad del artículo 3 del Real Decreto-ley enjuiciado, pues en él se autoriza la ratificación de una enmienda (la cuarta) al propio Convenio constitutivo del Fondo Monetario Internacional.

Las dudas de constitucionalidad planteadas en relación con la Ley 13/1999 tienen que ver, por un lado, con su aptitud para subsanar los defectos constitucionales del Real Decreto-ley 14/1998 y, por otro, con su condición de norma capaz de dar forma a la autorización parlamentaria exigida por el artículo 94.1 CE.

La Ley 13/1999 es fruto de la voluntad de las Cortes Generales. Se trata, pues, de una norma imputable a la misma voluntad que la requerida por el artículo 94.1 CE para la autorización previa de la prestación del consentimiento internacional del Estado. La competencia exclusiva de las Cortes Generales para autorizar esa prestación no es lo lesionado con el empleo de la ley, a diferencia de lo que sucede con la legislación gubernamental de urgencia. Pero la autorización previa de las Cortes regulada en el artículo 94.1 CE corresponde al ejercicio de una competencia que la Constitución califica de no legislativa; la cuestión no es ya, en consecuencia, si se ha prescindido o no de la intervención de un órgano, sino 
si la concreta competencia ejercida por éste lo ha sido por el cauce específicamente previsto por la Constitución a esos efectos. En definitiva, si la Constitución impone, en el caso de la autorización requerida para la asunción de compromisos internacionales, además de una reserva orgánica, una reserva de procedimiento, por tratarse de ejercicio de competencias constitucionales distintas.

Para las autorizaciones previstas en el artículo 94.1 CE, el artículo 74.2 de la Constitución establece un procedimiento parlamentario específico y diverso del legislativo ordinario o común, del que singularmente le distingue la circunstancia de que la posición del Senado se define en términos de mayor equilibrio frente a la que habitualmente es propia del Congreso de los Diputados. Así, mientras que en el procedimiento legislativo es norma que, de acuerdo con el artículo $90.2 \mathrm{CE}$, las discrepancias entre ambas Cámaras pueden resolverse en último término por decisión de la mayoría simple de la Cámara baja — también cuando el Senado ejerce un veto que, en realidad, sólo retrasa por dos meses la eficacia suficiente de la mayoría simple del Congreso de los Diputados-, en el caso del artículo 94.1 se prevé que las discrepancias se superen por medio de «una Comisión mixta compuesta de igual número de Diputados y Senadores", cuya propuesta debe ser aprobada por la mayoría de cada Cámara, imponiéndose finalmente, si la discrepancia persiste, la del Congreso de los Diputados, pero sólo y siempre por mayoría absoluta (artículo 74.2 CE).

Esa potenciación de la voluntad del Senado, en comparación con la más reducida importancia que se le atribuye en el procedimiento legislativo, hasta el punto de aproximar significativamente su intervención a la del Congreso - cuya negativa por mayoría simple sólo puede ser superada por una mayoría cualificada-, determina el proceso de formación de la voluntad parlamentaria en términos que se separan de cuanto es común en el conjunto de los procedimientos de las Cortes Generales, confiriéndose a la participación de la Cámara alta en aquel proceso una relevancia verdaderamente excepcional en nuestro sistema parlamentario, caracterizado por un notorio bicameralismo imperfecto... No se trata de un posible vicio en el procedimiento legislativo, regulado por normas infraconstitucionales, que es el caso planteado en la STC 97/2002, de 25 de abril, salvado en aquel caso, sino de inadecuada elección del procedimiento mismo, directamente establecido en la Constitución.

Ahora bien, el procedimiento del artículo 74.2 CE no puede dar cabida a cosa distinta que a la estricta autorización del artículo $94.1 \mathrm{CE}$, siendo por completo improcedente para la formación de otras voluntades parlamentarias, singularmente la legislativa en sentido propio. Los arts. 2 y 3 de la Ley 13/1999 autorizan la adhesión de España a determinados Acuerdos del Fondo Monetario Internacional y la ratificación de la cuarta enmienda al Convenio constitutivo del FMI, pero el artículo 2 y, de manera especial, los restantes preceptos de la Ley incluyen otras disposi- 
ciones cuyo contenido no se ajusta al continente de la simple autorización para la integración de normas foráneas.

En definitiva, por mínimo que sea el contenido normativo que las Cortes Generales consideren oportuno que acompañe a la autorización previa para la que son requeridas en virtud del artículo $94.1 \mathrm{CE}$, el procedimiento parlamentario pertinente será el legislativo, común o especial, que venga impuesto, en su caso, por la materia a que dicho contenido se refiera. Tal ha sido, por lo demás, la práctica observada hasta ahora por las Cortes Generales con ocasión de los distintos aumentos de la cuota de España en el Fondo Monetario Internacional.

Ello no significa, sin embargo, que la especificidad de este último procedimiento ( $y$, por tanto, su condición de reservado) haya de ceder necesariamente ante el procedimiento legislativo, cuando así lo imponga la afectación de otras materias. Por el contrario, lo que se impone es la duplicidad de procedimientos, distinguiendo con claridad la autorización propiamente dicha y la tramitación parlamentaria de las medidas legislativas necesarias como consecuencia de la autorización, que siempre ha de ser anterior. En otro caso la utilización exclusiva de la ley como cauce jurídico en el que se reduzcan a unidad una autorización ex artículo $94 \mathrm{CE}$, por un lado, y las medidas legislativas necesarias para la mejor integración de la norma externa, por otro, no deja de suponer el apartamiento del específico procedimiento establecido en la Constitución, y en tal sentido reservado, para dicha autorización.

Sobre esa base, entrando en el concreto enjuiciamiento de los artículos impugnados, en cuanto al artículo 2 hemos de declarar en esta Sentencia su inconstitucionalidad por vulneración de los arts. 94.1 d) y 74.2 CE.

Por lo que hace al artículo 3 hemos de señalar un dato especial que necesariamente justifica que respecto a él lleguemos a una conclusión diferente en su enjuiciamiento que en la del precepto anterior. Al respecto se debe señalar que antes de la aprobación de la Ley la autorización contenida en el artículo 3 había sido ya otorgada por las Cortes Generales por el cauce establecido en el artículo 74.2 CE. En efecto, dicha autorización fue dispensada por el Congreso de los Diputados y el Senado con fechas respectivas de 12 de noviembre y 9 de diciembre de 1998, de manera que la integración en el ordenamiento español de la cuarta enmienda al Convenio constitutivo del Fondo Monetario Internacional se ha verificado a través del procedimiento constitucionalmente obligado por el artículo 94 de la Constitución.

La STC 188/2005, de 7 de julio, resolvió la cuestión de inconstitucionalidad promovida por la Sección Sexta de la Sala de lo Contencioso-Administrativo del Tribunal Superior de Justicia de Madrid, en relación con el artículo 27.3 j) de la Ley Orgánica 2/1986, de 13 de marzo, de 
fuerzas y cuerpos de seguridad, por posible vulneración del principio non bis in idem (artículo 25.1 CE).

El artículo 27.3 j) de la Ley Orgánica 2/1986, de 13 de marzo, de fuerzas y cuerpos de seguridad, al tipificar como falta disciplinaria muy grave el «[H]aber sido sancionado por la comisión de tres o más faltas graves en el período de un año", resulta contrario a la garantía que representa el principio non bis in idem en su vertiente material o sustantiva, en la medida en que mediante dicho precepto se posibilita la duplicidad en el castigo a un determinado sujeto mediante la imposición de una doble sanción disciplinaria por la realización de unos mismos hechos, teniendo dichas sanciones un mismo fundamento. $Y$, dado que para la imposición de la sanción por la infracción muy grave tipificada en el precepto cuestionado es necesario seguir un nuevo procedimiento disciplinario distinto a los cumplimentados para la imposición de cada una de las tres (o más) sanciones por la comisión de las tres (o más) faltas graves que integran el tipo cuestionado, existiendo entre ellas, tal y como ya hemos visto, una triple identidad de sujeto, hechos y fundamento, la aplicación de dicho precepto implicaría también una lesión del principio non bis in idem, pero esta vez desde la perspectiva formal, procesal o, si se quiere más correctamente, procedimental.

Por todo ello, se declaró la inconstitucionalidad, y consiguiente nulidad, de la letra j) del apartado 3 del artículo 27 de la Ley Orgánica 2/1986, de 13 de marzo, de cuerpos y fuerzas de seguridad.

La STC 189/2005, de 7 de julio, puso fin al recurso de inconstitucionalidad promovido por sesenta y cuatro Diputados del Grupo Parlamentario Socialista en el Congreso de los Diputados contra los artículos $4,5,6,7,8,9,10,11,12,13,14$, disposición adicional segunda y disposición final primera, párrafo tercero, del Real Decreto-ley 7/1996, de 7 de junio, sobre medidas urgentes de carácter fiscal, y de fomento y liberalización de la actividad económica.

El Tribunal sentenció que los arts. 6, 7, 8, 9, 10, 11, 12, 13 y 14, la disposición adicional segunda, $y$, por consecuencia, la disposición final primera, párrafo tercero, del Real Decreto-ley 7/1996, de 7 de junio, han afectado a la esencia del deber de contribuir al sostenimiento de los gastos públicos que enuncia el artículo 31.1 CE, pues al modificar el régimen tributario de los incrementos y disminuciones patrimoniales en un tributo que, como el impuesto sobre la renta de las personas físicas constituye una de las piezas básicas de nuestro sistema tributario, se ha alterado el modo de reparto de la carga tributaria que debe levantar la generalidad de los contribuyentes, en unos términos que, conforme a la doctrina de este Tribunal (SSTC 182/1997, 137/2003, y 108/2004, ya citadas), están prohibidos por el artículo 86.1 CE. Se precisó que deben de- 
clararse no susceptibles de ser revisadas como consecuencia de la nulidad no sólo aquellas situaciones decididas mediante Sentencia con fuerza de cosa juzgada (artículo 40.1 LOTC), sino también por exigencia del principio constitucional de seguridad jurídica (artículo 9.3 CE), las establecidas mediante actuaciones administrativas firmes.

La STC 273/2005, de 27 de octubre, resolvió la cuestión de inconstitucionalidad planteada por la Sección Primera de la Audiencia Provincial de Ciudad Real, respecto al artículo 133, párrafo primero, del Código Civil.

Para el Tribunal, la privación al progenitor de la posibilidad de reclamar una filiación no matrimonial en los casos de falta de posesión de estado no resulta compatible con el mandato del artículo 39.2 CE de hacer posible la investigación de la paternidad ni, por ello, con el derecho a la tutela judicial efectiva (artículo 24.1 CE), en su vertiente de acceso a la jurisdicción.

El Tribunal también analizó si resulta posible una interpretación secundum constitutionem del precepto que impidiera apreciar su inconstitucionalidad. Al respecto se recuerda que en la jurisprudencia de la Sala Primera del Tribunal Supremo pueden encontrarse numerosas resoluciones (SSTS de 5 de noviembre de 1987, 10 de marzo de 1988, 8 de julio de 1991, 24 de junio de 1996, 30 de marzo de 1998, 19 de mayo de 1998, 20 de junio de 2000, 2 de octubre de 2000 y 22 de marzo de 2002) que, pese a la literalidad del párrafo primero del artículo $133 \mathrm{CC}$, reconocen al padre biológico legitimación para reclamar la filiación no matrimonial aunque falte la posesión de estado. Entendiendo que la interpretación literal del precepto llevaría a una transgresión del derecho fundamental a la tutela judicial efectiva que proclama el artículo $24.1 \mathrm{CE}$, se realiza una interpretación sistemática, más flexible, teniendo especialmente en cuenta el contenido del artículo $134 \mathrm{CC}$ y considerando que, en la medida en que éste legitima, en todo caso, al progenitor para impugnar la filiación contradictoria, también le está habilitando para que pueda ejercitar la acción de reclamación de la filiación extramatrimonial.

En el presente caso, a diferencia de los arts. 131 (legitimación para reclamar la filiación manifestada por la constante posesión de estado) y 132 (legitimación para reclamar la filiación matrimonial cuando falte la posesión de estado), el precepto cuestionado, en cuanto sólo reconoce legitimación al hijo para reclamar la filiación no matrimonial cuando falte la posesión de estado, no permite entender, sin forzar el sentido propio del enunciado, que el progenitor también se encuentra legitimado para reclamar dicha filiación. Así resulta claro que el legislador (como se explicitaba en la exposición de motivos que acompañaba al proyecto de Ley de reforma del Código civil, a la que antes se hizo referencia) no ha querido reconocer la legitimación para reclamar la filiación nada más que 
al hijo y, cuando éste fallezca, durante determinado plazo, a sus herederos, lo que impide una interpretación extensiva de la regla restrictiva del artículo $133 \mathrm{CC}$, por más que resulte plausible el intento jurisprudencial de salvar una evidente transgresión del derecho fundamental a la tutela judicial efectiva (STS de 19 de mayo de 1998). En consecuencia, no cabe eludir la inconstitucionalidad del precepto cuestionado por la vía de la interpretación secundum constitutionem.

La apreciación de la inconstitucionalidad de la insuficiencia normativa del precepto cuestionado exige que sea el legislador, dentro de la libertad de configuración de que goza, derivada de su posición constitucional y, en última instancia, de su específica legitimidad democrática (STC 55/1996, de 28 de marzo, FJ 6), el que regule con carácter general la legitimación de los progenitores para reclamar la filiación no matrimonial en los casos de falta de posesión de estado, con inclusión, en su caso, de los requisitos que se estimen pertinentes para impedir la utilización abusiva de dicha vía de determinación de la filiación, siempre dentro de límites que resulten respetuosos con el derecho a la tutela judicial efectiva (artículo 24.1 CE).

Finalmente, la STC 341/2005, de 21 de diciembre, se pronunció sobre el recurso de inconstitucionalidad interpuesto por sesenta y un Senadores del Grupo Parlamentario Socialista, contra diversos preceptos de la Ley de la Asamblea de Madrid 1/1998, de 2 de marzo, de fundaciones.

De acuerdo con el artículo 17.2 de la Ley de fundaciones de la Comunidad de Madrid, «no se podrán repudiar herencias ni dejar de aceptar donaciones sin la previa autorización del Protectorado o, en defecto de ésta, sin la aprobación judicial con audiencia del Ministerio Público». De este precepto, que reproduce lo dispuesto en el artículo 20.3 de la Ley 30/1994, se recurre únicamente su inciso final, pues los actores entienden que incurre en extralimitación competencial, dado que, según la disposición final primera, apartado 3, de la propia Ley 30/1994, se trata de una previsión perteneciente al campo de la "legislación procesal», de competencia exclusiva del Estado ex artículo 149.1.6 CE. Actualmente, el artículo 22.2 de la Ley 50/2002 no prevé la intervención judicial sustitutiva para estos supuestos, sino que realiza una remisión genérica a las eventuales "acciones de responsabilidad que correspondan contra los patronos, si los actos del Patronato fueran lesivos para la fundación, en los términos previstos en esta Ley".

La disposición cuestionada se inserta en una norma destinada a regular la aceptación o repudiación de herencias y donaciones y que exige, como medida de control del interés general, la previa autorización del Protectorado; ahora bien, la correcta previsión de una intervención judicial, con audiencia del Ministerio Fiscal, por mucho que responda a in- 
tereses jurídico-públicos, supone la articulación de un cauce procesal cuyo establecimiento es competencia exclusiva del Estado ex artículo 149.1.6 CE.

El artículo 24.3 de la Ley de fundaciones de la Comunidad de Madrid se impugna por reproducir lo dispuesto en el artículo 27.1 de la Ley 30/1994, de acuerdo con el cual «el Patronato podrá acordar la modificación de los Estatutos de la fundación siempre que resulte conveniente en interés de la misma y no lo haya prohibido el fundador, en cuyo caso requerirá la autorización previa del Protectorado". A este precepto se le atribuye la condición de "legislación civil» en la disposición final primera, apartado 2 b), de la propia Ley 30/1994.

Con la supresión del inciso final del antiguo artículo 27.1 de la Ley $30 / 1994$, el legislador estatal ha erigido a la voluntad del fundador, manifestada en el negocio jurídico fundacional, en límite infranqueable de eventuales modificaciones estatutarias, excluyendo la intervención sustitutiva del Protectorado. En todo caso estamos ante una norma que incide en el núcleo mismo de la institución fundacional, en cuanto persona jurídico-privada, que ha de reconducirse al ámbito propio de la "legislación civil» en el cual el Estado tiene, en principio, competencia exclusiva ex artículo 149.1.8 CE que únicamente reconoce competencia normativa a las Comunidades Autónomas para conservar, modificar o desarrollar los derechos civiles, forales o especiales "allí donde existan». Sentado lo anterior, y como quiera que la Comunidad Autónoma de Madrid no ostenta competencias sobre Derecho civil foral o especial, la regulación de este extremo contenida en el artículo 24.3 en cuestión se sitúa extramuros de sus facultades legislativas, por lo que la reproducción del precepto estatal incurre en el segundo supuesto de nuestro canon sobre las leges repetitae, debiendo considerarse inconstitucional por tal motivo.

\section{ORGANIZACIÓN TERRITORIAL DEL ESTADO}

En el ámbito político-constitucional ha de hacerse mención a los avatares que ha seguido el denominado "Plan Ibarretxe»: es preciso recordar, en primer término, que el 25 de octubre de 2003 el Gobierno Vasco aprobó la propuesta de nuevo Estatuto de Autonomía, «basado en la libre asociación con el Estado español», y acordó remitirlo al Parlamento autonómico; el 4 de noviembre de ese año la Mesa del Parlamentó decidió tramitar la propuesta por el procedimiento legislativo común; el día 13 de ese mismo mes el Gobierno de la Nación impugnó ante el Tribunal Constitucional los Acuerdos del Gobierno Vasco y de la Mesa de la Cámara.

Ya en 2004, el Pleno del Tribunal, en el Auto 135/2004, de 20 de abril, resolvió que 
"los Acuerdos que se impugnan, como puros actos de tramitación insertados en un procedimiento parlamentario, sólo despliegan efectos ad intra de ese procedimiento en tanto éste no concluya con la aprobación de la norma que a su través pretende generarse. La eventual inconstitucionalidad de los actos parlamentarios sólo es relevante cuando concluyen con una resolución, disposición o acto que se integra en el Ordenamiento (y deberá verificarse con motivo del juicio de constitucionalidad que eventualmente se inste respecto de esa disposición, resolución o acto), o cuando, sin finalizar el procedimiento en el que se insertan, producen una lesión inmediata de derechos fundamentales de los sujetos legitimados para participar en el procedimiento. Aquel control se verificará por vía del recurso y de la cuestión de inconstitucionalidad; éste mediante el recurso de amparo. La impugnación del título $\mathrm{V}$ queda descartada, por principio, si pretende dirigirse contra el acto de trámite antes de que el procedimiento concluya, pues, según se ha dicho, el título $V$, en un entendimiento sistemático de la Ley en la que se incluye, establece un procedimiento de control de constitucionalidad de disposiciones y resoluciones imputables a la Comunidad Autónoma por conducto de los órganos expresivos de su voluntad institucional, supuesto en el que manifiestamente no pueden comprenderse los actos que se insertan en un procedimiento de gestación (incierta) de esa voluntad. Y debe también excluirse una vez finalizado el procedimiento, si éste lo hace con una norma con rango de ley.

En definitiva, en los Acuerdos del Gobierno Vasco de 25 de octubre de 2003 y de la Mesa del Parlamento Vasco de 4 de noviembre de 2003 no concurre el presupuesto procesal insubsanable de constituir objetos idóneos de la impugnación regulada en el artículo 161.2 CE y en el título V de la Ley Orgánica del Tribunal Constitucional.

En virtud de lo expuesto, el Pleno acuerda la inadmisión de la impugnación y el archivo de las actuaciones.».

En el Pleno del Parlamento Vasco de 30 de diciembre de 2004 resultó aprobada la propuesta del nuevo Estatuto político de la Comunidad de Euskadi con los votos favorables del Partido Nacionalista VascoEusko Alkartasuna (33), Izquierda Unida (3) y Sozialista Aberzaleak (3) y los votos contrarios del Partido Popular(18), Partido Socialista (13), Unidad Alavesa (1) y Sozialista Aberzaleak (3).

La propuesta se tramitó ante el Congreso de los Diputados como una iniciativa de reforma de Estatuto de Autonomía y se sometió a debate de totalidad el día 1 de febrero de 2005, siendo rechazada por 313 votos en contra, 29 a favor y 2 abstenciones, quedando, en consecuencia, rechazada la propuesta (Diario de Sesiones del Congreso de los Diputados, n. ${ }^{\circ} 65$, de 1 de febrero). 
Además, ha de darse cuenta de los trámites para la reforma de dos Estatutos de Autonomía, el de la Comunidad Valenciana y el de Cataluña.

El 1 de julio, las Cortes Valencianas, en sesión plenaria, aprobaron la Proposición de Ley Orgánica de reforma del Estatuto de Autonomía de la Comunidad Valenciana, que fue debatida y votada favorablemente por el Pleno del Congreso de los Diputados en su sesión de 23 de septiembre, para, a continuación, continuar su curso parlamentario en la Comisión Constitucional ${ }^{14}$.

Por su parte, el Pleno del Parlamento de Cataluña, en sesión celebrada los días 28, 29 y 30 de septiembre de 2005, debatió el Dictamen de la Comisión de Organización y Administración de la Generalidad y Gobierno Local sobre la Propuesta de proposición de ley orgánica por la que se establece el Estatuto de autonomía de Cataluña y se deroga la Ley Orgánica 4/1979, de 18 de diciembre, de Estatuto de autonomía de Cataluña; los votos particulares, las enmiendas reservadas y las enmiendas subsiguientes al Dictamen del Consejo Consultivo. Finalmente, el Pleno del Parlamento, con el apoyo de 120 votos, que superan la mayoría requerida de dos tercios (90), aprobó la citada Propuesta ${ }^{15}$, que fue debatida y votada favorablemente por el Pleno del Congreso de los Diputados en su sesión de 4 de noviembre, para, a continuación, continuar su curso parlamentario en la Comisión Constitucional ${ }^{16}$.

Ha de señalarse, en otro orden de cosas, la celebración, el 10 de septiembre, de la Segunda Conferencia de Presidentes, que reunió al Presidente del Gobierno con los de las Comunidades y Ciudades Autónomas para debatir sobre la financiación de la sanidad, que tuvo continuidad en el Acuerdo del Consejo de Política Fiscal y Financiera de 13 de septiembre, y que, entre otros instrumentos, se ha concretado en el Real Decreto-Ley 12/2005, de 16 de septiembre, por el que se aprueban determinadas medidas urgentes en materia de financiación sanitaria (BOE n. ${ }^{\circ} 223$, de 17 de septiembre; convalidación: 29 de septiembre, BOE n. ${ }^{\circ} 240$, de 7 de octubre). En función de los Acuerdos señalados, el Gobierno aportará para la financiación de la sanidad 3.042,4 millones de euros para el año 2006 y 3.142,4 millones para el año 2007. Igualmente, con dichos acuerdos las Comunidades Autónomas asumen compromisos para la mejora de la eficiencia del gasto sanitario.

\footnotetext{
${ }^{14}$ Más información en http://www.cortsvalencianes.es y http://www.congreso.es

${ }^{15} \mathrm{http} / / /$ www.parlament-cat.net/porteso/estatut/estatuto.pdf

16 Más información en http://www.congreso.es
} 
En el ámbito de la jurisprudencia constitucional han de citarse las siguientes sentencias:

La STC 33/2005, de 17 de febrero, puso fin al conflicto positivo de competencia promovido por el Consejo Ejecutivo de la Generalidad de Cataluña frente al Real Decreto 2200/1995, de 28 de diciembre, por el que se aprueba el Reglamento de la infraestructura para la calidad y la seguridad industrial, y frente al Real Decreto 85/1996, de 26 de enero, por el que se establecen normas para la aplicación del Reglamento (CEE) 1836/93, del Consejo, de 29 de junio, por el que se permite que las empresas del sector industrial se adhieran con carácter voluntario a un sistema comunitario de gestión y auditoría medioambientales.

El Tribunal declaró que el artículo 2 y la disposición adicional segunda del Real Decreto 85/1996, de 26 de enero, por el que se establecen normas para la aplicación del Reglamento (CEE) 1836/1993, del Consejo, vulneran las competencias de la Generalidad de Cataluña en materia de medio ambiente.

La STC 35/2005, de 17 de febrero, resolvió el recurso de inconstitucionalidad planteado por el Consejo de Gobierno de la Junta de Andalucía contra los arts. 19.3, 23.5 c) y 23.ter.3 de la Ley 4/1989, de 29 de marzo, de conservación de los espacios naturales y de la flora y fauna silvestres, en la redacción que a dichos preceptos otorga la disposición adicional cuarta de la Ley 15/2002, de 1 de julio, por la que se declara el Parque Nacional marítimo-terrestre de las Islas Atlánticas de Galicia. Los preceptos impugnados regulan la aprobación de los Planes directores de uso y gestión (artículo 19.3), la elaboración y aprobación de los planes sectoriales que, en su caso, desarrollen dichos Planes rectores (artículo 23.5.c) y el régimen de nombramiento y adscripción del Director-Conservador de los parques nacionales (artículo 23.ter.3).

El Tribunal estimó parcialmente el recurso y declaró que son inconstitucionales los arts. 19.3, salvo su inciso «los Planes Rectores de Uso y Gestión de los Parques Nacionales serán aprobados por la Comunidad Autónoma correspondiente»; 23.5 c); y 23.ter.3, todos ellos de la Ley 4/1989, de 27 de marzo, de conservación de los espacios naturales y de la flora y fauna silvestres, en la redacción dada por dicha disposición adicional cuarta de la Ley 15/2002.

En sentido idéntico se pronunció la STC 36/2005, de 17 de febrero de 2005, en el recurso planteado por el Gobierno de Aragón.

La STC 81/2005, de 6 de abril, puso fin al recurso de inconstitucionalidad interpuesto por el Parlamento de Andalucía contra los arts. 
3.3, 4.2 a) , 6, 7, 8, 9.3, 10.5 y disposición final primera de la Ley 3/1999, de 11 de enero, por la que se crea el Parque Nacional de Sierra Nevada.

El Tribunal declaró que son inconstitucionales, con los efectos señalados en el fundamento jurídico 13, los artículos 4.2 a), inciso «de la Comisión Mixta de Gestión»; 6; 7, apartados 1, inciso "adscrito a efectos administrativos al Ministerio de Medio Ambiente», 2 d), e), f), g), h), i), j), k), y II), 3 y $4 ; 8 ; 9.3$ y 10.5 de dicha Ley. En segundo lugar, declaró que su artículo 3.3, interpretado de acuerdo con lo indicado en el fundamento jurídico 10, es constitucional.

En la STC 100/2005, de 19 de abril de 2005, y a propósito del recurso de inconstitucionalidad núm. 1566/99, interpuesto por el Consejo de Gobierno de la Junta de Andalucía contra los arts. 3.3, 4.2 a), 6, 7, 8, 9.2 y $3,10.2,3,4$ y 5 y disposición final primera de la Ley 3/1999, de 11 de enero, por la que se crea el Parque Nacional de Sierra Nevada, se estimó parcialmente el recurso y, en consecuencia, se declaró la pérdida de objeto del recurso respecto de los arts. 3.3, 4.2 a), 6, 7, 8, 9.3, 10.5 y disposición final primera de la Ley impugnada, y la inconstitucionalidad del artículo 10.4 b).

La STC 101/2005, de 19 de abril, resolvió el conflicto positivo de competencia planteado por el Consejo de Gobierno de la Junta de Andalucía contra los arts. 1, 2 y 3 y diversos preceptos del anexo del Real Decreto 1803/1999, de 26 de noviembre, por el que se aprueba el Plan director de la red de parques nacionales.

El Tribunal lo estimó parcialmente y, en consecuencia, declaró que vulneran las competencias de la Comunidad Autónoma de Andalucía los siguientes apartados del anexo de dicho Real Decreto que contiene el Plan director de la red de parques nacionales: apartado 3, epígrafes 3 a), b), j), último inciso y l); 4 d), segundo inciso, y f); apartado 4, epígrafes 4; 5; 6; y 7; apartado 5, epígrafes 1, último inciso de las letras c) y e); 3 a), b), c) y f); $4 ; 5$ a) y c); $6 ; 8$, salvo el inciso "renovar la imagen corporativa y la identidad gráfica de la red" de su letra a) y 9 a) y c); y apartado 8.

La STC 154/2005, de 9 de junio, resolvió los conflictos positivos de competencia acumulados $1903 / 95$ y $3768 / 95$, promovidos por el Consejo Ejecutivo de la Generalidad de Cataluña contra el Real Decreto 2364/1994, de 9 de diciembre, que aprueba el Reglamento de seguridad privada, y la Orden del Ministerio de Justicia e Interior de 7 de julio de 1995, que lo desarrolla.

El Tribunal estimó parcialmente el conflicto positivo de competencia planteado por el Consejo Ejecutivo de la Generalidad de Cataluña en 
relación con el Real Decreto 2364/1994, de 9 de diciembre, por el que se aprueba el Reglamento de seguridad privada y, en consecuencia, declaró: $1 .^{\circ}$ que vulneran las competencias de la Generalidad de Cataluña las facultades de ejecución atribuidas a órganos de la Administración General del Estado por los arts. 65.3 y 81.1 c) y 2 del Reglamento de seguridad privada. $2 .^{\circ}$ Estimó parcialmente el conflicto positivo de competencia interpuesto por el Consejo Ejecutivo de la Generalidad de Cataluña contra la Orden del Ministerio de Justicia e Interior de 7 de julio de 1995, y, en consecuencia, declaró que vulneran las competencias de la Generalidad de Cataluña las facultades de ejecución atribuidas a órganos de la Administración General del Estado por el párrafo tercero del artículo 14 de dicha Orden Ministerial.

La STC 212/2005, de 21 de julio, trae causa del conflicto positivo de competencia promovido por el Consejo Ejecutivo de la Generalidad de Cataluña frente a la Orden de 1 de julio de 1996, del Ministerio de Educación y Cultura, por la que se conceden ayudas de educación especial para el curso 1996-1997.

Según el Tribunal, la tacha relativa a la incompetencia estatal para regular la tramitación de las ayudas ha se ser confirmada, "pues la regulación de todos estos aspectos no constituyen normas básicas para el desarrollo del artículo $27 \mathrm{CE}$, sino normas reguladoras del procedimiento de gestión de las ayudas que se inscribe en el ámbito de la competencia de la Generalidad en materia de enseñanza, y ya hemos declarado con reiteración que las normas procedimentales ratione materiae deben ser dictadas por las Comunidades Autónomas competentes en el correspondiente sector material, respetando las reglas del procedimiento administrativo común (por todas, STC 98/2001, de 5 de abril, FJ 8, con cita de la STC 227/1998, de 26 de noviembre, FJ 32). Por tanto, debe ser la Generalidad de Cataluña quien establezca el procedimiento de gestión, control y resolución de las solicitudes de beca que se presenten y determine los órganos competentes para ello" (STC 188/2001, FJ 11). Respecto a la disposición final tercera, que «autoriza a la Dirección General de Formación Profesional y Promoción Educativa para aplicar y desarrollar lo dispuesto en la presente Orden", concluyó que también vulnera las competencias de la Generalidad de Cataluña por un doble motivo: en primer lugar, porque la atribución a un órgano estatal de funciones aplicativas de la Orden que, como hemos señalado, corresponden a la Generalidad de Cataluña, determina la infracción del orden constitucional de competencias. Y, en segundo lugar, porque la previsión de que dicha Dirección General, en la dimensión normativa, pueda continuar desarrollando lo regulado en la Orden conlleva una infracción de la perspectiva formal de las normas básicas, pues ya dijimos que «no resulta posible que las bases continúen siendo reformuladas de modo sucesivo a través de instrumentos normativos de rango inferior a la Ley y al Real 
Decreto" (aunque sin excluir la Orden Ministerial capaz de contener regulación básica en esta materia en supuestos muy excepcionales, como ya hemos manifestado más atrás). Por ello, dicha reformulación sólo es aceptable a través de resoluciones administrativas (como serían las que nos ocupan, conferidas a la Dirección General de Formación Profesional y Promoción Educativa) «en la medida en que, simplemente, realizan la convocatoria anual y no incorporan prescripciones adicionales a las contenidas en las Órdenes Ministeriales respecto a las condiciones de obtención de las ayudas... [y, por ello, en esa sola medida] no contravienen tampoco el principio de no reformulación sucesiva de la normativa básica" (STC 242/1999, de 21 de diciembre, FFJJ 8 y 9). Por lo que, a sensu contrario, en este caso la disposición vulnera las competencias de la Generalidad al prever el desarrollo normativo de la Orden por aquella Dirección General. En conclusión, en razón a la doble tacha apreciada, todos los artículos de este segundo grupo vulneran las competencias de la Generalidad de Cataluña.

Por ello, se estimó parcialmente el conflicto positivo de competencia, declarando que vulneran las competencias de la Generalidad de Cataluña los artículos quinto, sexto, séptimo, octavo, noveno, décimo, undécimo, duodécimo, decimocuarto, decimoquinto y la disposición final tercera de dicha Orden.

En la STC 253/2005, de 11 de octubre, se analizó el conflicto positivo de competencia promovido por el Gobierno de la Nación frente al Decreto del Gobierno Vasco 63/1998, de 31 de marzo, por el que se aprueba el Acuerdo con las organizaciones sindicales sobre modernización en la prestación del servicio público de la Justicia y su repercusión en las condiciones de trabajo del personal al servicio de la Administración de Justicia.

El Tribunal concluyó que al Estado le corresponde la regulación legal o reglamentaria de los aspectos esenciales del régimen retributivo de los cuerpos de funcionarios al servicio de la Administración de Justicia, considerando como tales a todos aquellos elementos que garantizan la necesaria unidad y homogeneidad de dichos cuerpos nacionales. Sin embargo, esta competencia estatal no puede excluir que las Comunidades Autónomas competentes regulen determinados aspectos del sistema retributivo siempre que la normativa estatal sea respetada, es decir, siempre que la misma no resulte cuestionada, enervada o alterada en su aplicación.

En consecuencia, estimó parcialmente el conflicto y declaró que las competencias controvertidas contenidas en el capítulo XIII, título III y, por conexión, el anexo IV, del citado Acuerdo con las organizaciones sindicales, no vulneran las competencias del Estado, si se interpretan de acuerdo con lo indicado en el fundamento jurídico 14. 
La STC 331/2005, de 15 de diciembre, resolvió el recurso de inconstitucionalidad interpuesto por el Presidente del Gobierno frente a la Ley del Parlamento de Andalucía 8/1999, de 27 de octubre, del espacio natural de Doñana.

EI Tribunal recuerda que en la STC 194/2004, FJ 14 c), consideró básica la representación paritaria de las Administraciones estatal y autonómica y no apreció vulneración alguna de las bases estatales en el artículo 16, que regula las funciones del consejo de participación. Debe, no obstante, hacerse mención de su epígrafe 7 («aprobar los planes sectoriales que en su caso desarrollen el plan rector de uso y gestión"). A esta función, atribuida por la Ley 41/1997 al Patronato en su artículo 23.bis.6 c), le negamos su carácter básico por comportar carácter decisorio e imponerse así a la Comunidad Autónoma en su función gestora e impedir el ejercicio por ésta de una competencia de gestión que tiene atribuida y que es, por ello, indisponible para el Estado [STC 194/2004, FJ 14 c)].

Igual criterio hay que mantener ahora respecto de esta función ejecutiva atribuida a un órgano cuyas funciones son de propuesta. En este caso, la Ley autonómica tampoco puede atribuir a un órgano de cooperación de carácter predominantemente consultivo y deliberante y, en todo caso, no ejecutivo, en el que se integran, además de la Comunidad Autónoma, representantes del Estado, de los entes locales y de intereses sociales privados, el ejercicio de funciones administrativas de carácter aplicativo o ejecutivo que, por ser de tal naturaleza, han de ejercerse por la Comunidad Autónoma en régimen de propia responsabilidad, toda vez que las competencias son, además de indisponibles, irrenunciables. EI empleo de técnicas de cooperación y coordinación, absolutamente imprescindible en múltiples ocasiones para el funcionamiento del Estado autonómico, no permite, sin embargo, alterar el principio de competencia, de manera que mientras que responde adecuadamente a la finalidad del principio de cooperación el establecimiento de órganos de deliberación y consulta, como el presente, con funciones de mera propuesta, no se acomoda al orden constitucional de distribución de competencias que estos órganos, integrados por varias Administraciones y no sólo por la Administración autonómica e, incluso, por representaciones de los intereses privados, ejerzan funciones administrativas que están atribuidas estatutariamente y con carácter exclusivo a la Comunidad Autónoma de Andalucía. Por tanto, los arts. 14, 15 y 16 resultan constitucionales, salvo el apartado 7 de este último que, por lo dicho, es inconstitucional.

Finalmente, la STC 332/2005, de 15 de diciembre, se pronunció sobre los recursos de inconstitucionalidad interpuestos, respectivamente, por los Gobiernos de la Generalidad de Cataluña, del Principado de Asturias, de Aragón y de la Junta de Comunidades de Castilla-La Mancha contra los artículos 7 y 8 , y las disposiciones transitoria y final segunda 
del Real Decreto-ley 7/2000, de 23 de junio, de medidas urgentes en el sector de las telecomunicaciones

A juicio del Tribunal, debe rechazarse que la competencia relativa al tráfico y a la circulación de vehículos a motor (artículo 149.1.21 CE) faculte al Estado para determinar, con carácter vinculante, la figura administrativa que permite que los particulares presten el servicio de ITV, toda vez que su solvencia técnica y económica en nada depende de dicho título, sino del cumplimiento de los requisitos que a tales efectos determine el Estado. En efecto, resulta a todas luces excesivo intentar vincular el título administrativo que permite la participación de los particulares en la prestación del servicio de ITV con la garantía de dicha seguridad.

La previsión de que la participación de los particulares en la prestación del servicio de ITV se produzca necesariamente a través de la técnica de la autorización administrativa reglada, de modo que las Comunidades Autónomas estén obligadas a conceder dicha autorización a todas las instalaciones que acrediten el cumplimiento de los requisitos técnicos establecidos reglamentariamente, no puede considerarse materialmente básica desde la perspectiva del artículo 149.1.13 CE sin vaciar de contenido las competencias en materia de industria que los respectivos Estatutos de Autonomía atribuyen con carácter exclusivo a las Comunidades Autónomas recurrentes. Para llegar a esta conclusión hay que tener en cuenta, en primer lugar, que dicha previsión no constituye un aspecto básico de la ordenación de la actividad económica de prestación del servicio de ITV, como la que impone que este servicio pueda prestarse por las Administraciones competentes, por sociedades de economía mixta o por los particulares, puesto que carece del carácter genérico y, por lo tanto, susceptible de diversos desarrollos, de unas bases que, constitucionalmente, deben proyectarse sobre la planificación general de la actividad económica. Aunque este hecho no ha impedido que en no pocas ocasiones hayamos reconocido el carácter básico de medidas singulares, de naturaleza incluso ejecutiva, por su incidencia en el desarrollo de la economía, en los objetivos de política económica del Gobierno o en la consecución de los fines propuestos dentro de la ordenación de un determinado sector, en este caso no puede aceptarse que dicha competencia faculte al Estado a hacer depender la participación de los particulares en la prestación del servicio de ITV única y exclusivamente del cumplimiento de unos requisitos técnicos que las Comunidades Autónomas deben limitarse a verificar a través del otorgamiento de la correspondiente autorización administrativa.

Como el propio Tribunal ha "reconocido reiteradamente (por todas, SSTC 203/1992, de 26 de octubre, FJ 2; 243/1994, de 21 de julio, FJ 2; y $33 / 2005$, de 17 de febrero, FJ 5), la competencia autonómica en materia de industria faculta a sus titulares, no sólo a regular los procesos industriales o de fabricación, sino también a ordenar los sectores industriales, 
lo cual incluye, como es lógico, la utilización de potestades normativas.... Pues bien, puesto que la determinación del régimen jurídico que habilita a los particulares a prestar el servicio de ITV afecta directamente a la ordenación de este sector industrial, por cuanto puede predeterminar, como en el caso de la norma aquí analizada, que las Comunidades Autónomas estén obligadas a otorgar la correspondiente autorización administrativa sin poder tener en cuenta otros factores que consideren relevantes, tales como la distribución territorial de las instalaciones de ITV o la forma y condiciones de prestación del servicio, que no están directamente relacionados con la seguridad vial, debe concluirse que se trata de una competencia que corresponde a las Comunidades Autónomas recurrentes. Por todo ello procede declarar la inconstitucionalidad de la parte del artículo 7.2 del Real Decreto-ley 7/2000 ahora analizada..., esta constatación en nada impide que sea el Estado quien establezca con carácter general todos aquellos requisitos técnicos relativos a los vehículos inspeccionados, las instalaciones de ITV y las empresas titulares de las mismas que afecten de modo directo e inmediato a la seguridad vial.

En consecuencia, el Tribunal declaró a) Que el artículo 7.2 del Real Decreto-ley vulnera las competencias autonómicas en materia de industria al imponer la autorización administrativa como título habilitante para que los particulares puedan participar en la prestación del servicio de ITV; b) Que la remisión reglamentaria contenida en la última frase del artículo 7.2 en relación con la determinación de los requisitos técnicos que deben cumplir las instalaciones de ITV debe entenderse dirigida a la Administración General del Estado, sin perjuicio de que las Comunidades Autónomas con competencia exclusiva en materia de industria puedan dictar disposiciones complementarias de las del Estado, siempre que no violen los mandatos o impidan alcanzar los fines perseguidos por la legislación estatal. 